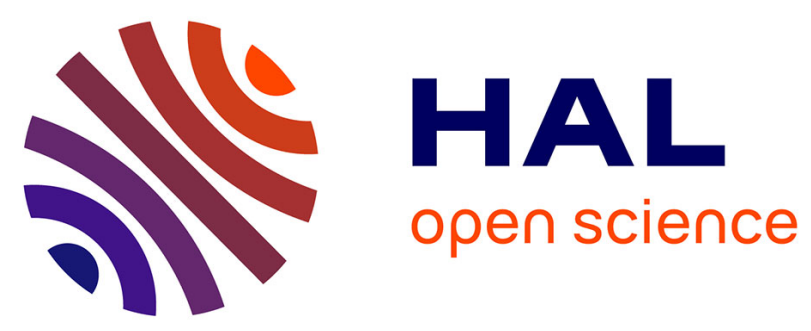

\title{
Fe and Co selective substitution in Ni2MnGa: Effect of magnetism on relative phase stability
}

\author{
Xavier Moya, Lluis Manosa, Antoni Planes, Daniel Enrique Soto-Parra, \\ Horacio Flores-Zuñiga, Francisco Alvarado-Hernandez, Raul Ochoa-Gamboa, \\ Jose Andres Matutes-Aquino, David Rios-Jara
}

\section{To cite this version:}

Xavier Moya, Lluis Manosa, Antoni Planes, Daniel Enrique Soto-Parra, Horacio Flores-Zuñiga, et al. Fe and Co selective substitution in Ni2MnGa: Effect of magnetism on relative phase stability. Philosophical Magazine, 2010, 90 (20), pp.2771-2792. 10.1080/14786431003745393 . hal-00596603

\section{HAL Id: hal-00596603 https://hal.science/hal-00596603}

Submitted on 28 May 2011

HAL is a multi-disciplinary open access archive for the deposit and dissemination of scientific research documents, whether they are published or not. The documents may come from teaching and research institutions in France or abroad, or from public or private research centers.
L'archive ouverte pluridisciplinaire $\mathbf{H A L}$, est destinée au dépôt et à la diffusion de documents scientifiques de niveau recherche, publiés ou non, émanant des établissements d'enseignement et de recherche français ou étrangers, des laboratoires publics ou privés. 


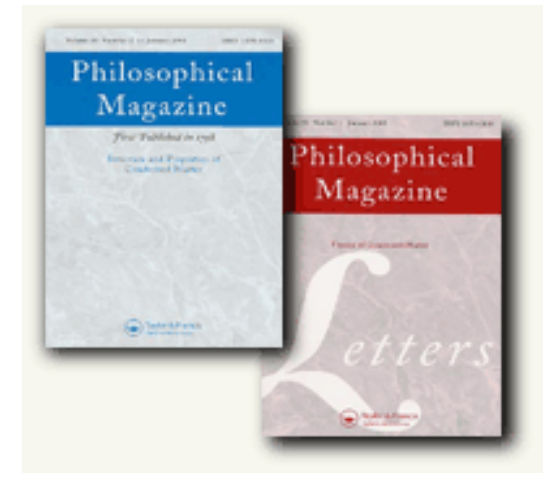

\section{Fe and Co selective substitution in Ni2MnGa: Effect of magnetism on relative phase stability}

\begin{tabular}{|r|l|}
\hline Journal: & Philosophical Magazine \& Philosophical Magazine Letters \\
\hline Manuscript ID: & TPHM-10-Jan-0029.R1 \\
\hline Journal Selection: & Philosophical Magazine \\
\hline Author: & 23-Feb-2010 \\
\hline Complete List of Authors: & $\begin{array}{l}\text { Moya, Xavier; Universitat de Barcelona, Estructura i Constituents de } \\
\text { la Matèria } \\
\text { Manosa, Lluis; Universitat de Barcelona, Estructura i Constituents } \\
\text { de la Materia } \\
\text { Planes, Antoni; Universitat de Barcelona, Estructura i Constituents } \\
\text { de la Materia } \\
\text { Soto-Parra, Daniel; Universitat de Barcelona, Estructura i } \\
\text { Constituents de la Materia } \\
\text { Flores-Zuñiga, Horacio; Centro de Investigacion en Materiales } \\
\text { Avanzados } \\
\text { Alvarado-Hernandez, Francisco; Centro de Investigacion en } \\
\text { Materiales Avanzados } \\
\text { Ochoa-Gamboa, Raul; Centro de Investigacion en Materiales } \\
\text { Avanzados } \\
\text { Matutes-Aquino, Jose; Centro de Investigacion en Materiales } \\
\text { Avanzados } \\
\text { Rios-Jara, David; Instituto Potosino de Investigacion Cientifica y } \\
\text { Tecnologica }\end{array}$ \\
\hline Keywords: & $\begin{array}{l}\text { phase transitions, phase transformations, martensitic } \\
\text { transformations }\end{array}$ \\
\hline Keywords (user supplied): & \begin{tabular}{l} 
Magnetic shape memory alloys, Ni2MnGa \\
\hline
\end{tabular} \\
\hline
\end{tabular}




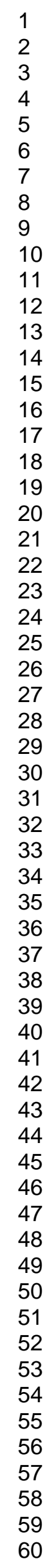

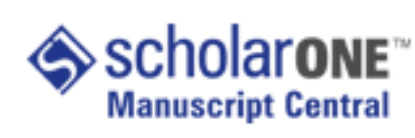

http://mc.manuscriptcentral.com/pm-pml 
Philosophical Magazine

Vol. 00, No. 00, 00 Month 200x, 1-15

\title{
RESEARCH ARTICLE
}

\section{Fe and Co selective substitution in $\mathrm{Ni}_{2} \mathrm{MnGa}$ : Effect of magnetism on relative phase stability}

\author{
D. E. Soto-Parra ${ }^{a}$, X. Moya ${ }^{a^{\dagger}}$, L. Mañosa ${ }^{a}$, A. Planes ${ }^{a^{\ddagger}}$, H. Flores-Zúñiga $\mathrm{b}^{\S}$, F. \\ Alvarado-Hernández ${ }^{\mathrm{b}}$, R. A. Ochoa-Gamboa ${ }^{\mathrm{b}}$, J. A. Matutes-Aquinob ${ }^{\mathrm{b}}$, and D. \\ Ríos-Jara ${ }^{\mathrm{c}}$ \\ ${ }^{a}$ Departament d'Estructura i Constituents de la Matèria, Facultat de Física, Universitat \\ de Barcelona, Diagonal 647, E-08028 Barcelona, Catalonia, Spain; ${ }^{\mathrm{b}}$ Centro de \\ Investigación en Materiales Avanzados S.C. Miguel de Cervantes 120, Complejo \\ industrial Chihuahua. 31109 Chihuahua México; ${ }^{\mathrm{c}}$ Instituto Potosino de Investigación \\ Científica y Tecnológica, Camino a la Presa San José 2055. Col. Lomas 4 sección, 78216 \\ San Luis Potosí, S.L.P. México
}

(February 23, 2010)

\begin{abstract}
We studied the effect of $\mathrm{Fe}$ and $\mathrm{Co} 3 d$ elements selective substitution on the structural and magnetic phase transitions in the prototypical magnetic shape memory alloy Ni-MnGa. We determined the phase diagram for each elemental doping substitution by means of calorimetry and ac susceptibility measurements. An effort was made to substitute each constituent element by same amounts of doping and to study the role of parameters other than electronic concentration in controlling phase stability. Specifically, selective doping with atoms of similar atomic radii but different magnetic properties allowed to investigate the role of magnetic interactions on the relative phase stability of the ternary compound. We determined the entropy change associated with the martensitic transition for each quaternary alloy to obtain further information on the effect of magnetism on the relative stability of the involved phases exhibited by these compounds.
\end{abstract}

Keywords: Magnetic shape memory alloys; $\mathrm{Ni}_{2} \mathrm{MnGa}$; phase transitions; phase diagrams

\section{Introduction}

Ni-Mn based Heusler alloys are currently under active research due to the magnetic and structural phase transitions they exhibit [1-4]. In these compounds, the existence of structural phase transitions in magnetically ordered states is of great importance both from the fundamental and the application points of view and leads to very interesting phenomena such as magnetic shape memory effects [5-7], large magnetoresistance [8-10] and large magnetocaloric effects [11-17]. The cooccurrence of various of these effects in single alloys belonging to this family makes these compounds multifunctional materials. The interplay between structural and magnetic degrees of freedom is at the origin of such multifunctionality. Thus, a detailed understanding of the phase diagrams of these particular Heusler alloys

\footnotetext{
${ }^{\dagger}$ Present address: Department of Materials Science and Metallurgy, University of Cambridge, Pembroke Street, Cambridge CB2 3QZ, United Kingdom.

† Corresponding author. Email: toni@ecm.ub.es

§Present address: Maestría en Procesos y Materiales. Unidad Académica de Ingeniería. Universidad Autónoma de Zacatecas. Carretera a la Bufa km. 2, Col. Centro 98000 Zacatecas, Zac. México.

ISSN: 1478-6435 print/ISSN 1478-6443 online

(C) 200x Taylor \& Francis

DOI: $10.1080 / 1478643$ YYxxxxxxxx

http://www.informaworld.com
} 
is needed in order to improve their functional properties and to search for new applications.

The most studied system so far belonging to this alloy family is the prototypical magnetic shape memory alloy Ni-Mn-Ga, for which magnetic field induced strains as large as $10 \%$ in a field of $1 \mathrm{~T}$ have been reported [18]. From a fundamental point of view, this alloy undergoes a complex multi-stage transformation process from a high temperature paramagnetic cubic phase to a low temperature ferromagnetic martensitic phase. At intermediate temperatures it shows precursor tweed textures which may lock into a modulated premartensitic structure via a first-order phase transition at $T_{I}\left(M_{s}<T_{I}<T_{C} ; M_{s}\right.$ martensite start temperature, $T_{C}$ Curie point) [19]. This behavior is related to low resistance against distortions of $\{110\}$ planes along $\langle 1 \overline{1} 0\rangle$ directions, as evidenced by the features of the low energy $\mathrm{TA}_{2}$ acoustic phonon branch [20-22] and the low value of the shear elastic constant $C^{\prime}=\left(C_{11}-C_{12}\right) / 2$ [23-25]. Furthermore, recent experiments have shown the opening of a pseudogap close to the Fermi energy at $T_{I}$, which suggests that the premartensitic transition corresponds to a nesting feature of a single band [26]. In addition to the martensitic and premartensitic transformations, intermartensitic transformations also exist in alloys with $M_{s}$ near or higher than room temperature. Previous investigations have shown that such intermartensitic transformations are first-order phase transitions between different martensitic structures, with characteristic temperature $T_{I M}\left(<M_{s}\right)$ [27-29]. Several intermartensitic phases have been found, which have modulated lattices with different periodicity of stacking sequences of $\{110\}$ planes along $\langle 1 \overline{1} 0\rangle$ directions [27-33]. The particular structures and transformation temperatures depend on stress and chemical composition $[29,33]$.

Despite previous attempts of characterizing the structural transitions exhibited by these compounds, further experiments are crucial for comprehending their rich functional properties. Premartensitic and specially intermartensitic transitions have only been observed for a restricted number of magnetic shape memory alloys and are not yet fully understood. Also, a better understanding of the parameters which govern phase stability is necessary to optimize materials design and performance. Recently, we showed that selective partial substitution of $3 d$ elements in Ni-Mn-Ga alloys is a useful tool to study the role of electron concentration on the structural and magnetic phase transitions exhibited by these materials. Specifically, we studied the effect of Fe addition on the Curie, premartensitic and martensitic transitions and we determined a detailed phase diagram of quaternary Ni-Mn-Ga-Fe alloys for low Fe concentrations [34]. Previously, the study of doping in Ni-Mn-Ga alloys had been focused only on its effect on the martensitic and the ferromagnetic phase transitions [35-46]. Here, we extend previous studies by means of investigating the dependence of all transition temperatures $\left(M_{s}, T_{I}, T_{I M}\right.$ and $T_{C}$ ) on $\mathrm{Fe}$ and Co $3 d$ transition elements doping, with concentrations up to $\sim 5 \%$ in both cases. The introduction of such elements of similar atomic radii (and therefore similar volume effects) but different magnetic properties allows study of the effect of magnetic interactions on the structural transitions. We also studied the effect of doping on the entropy change associated with the martensitic transition. Comparison of the composition dependence of $\Delta S$ for the studied quaternary compounds and the parent ternary Ni-Mn-Ga system provides further information on the role of magnetism on the relative phase stability of these alloys. 


\section{Experimental Details}

Polycrystalline Ni-Mn-Ga- $Z$ ( $Z=\mathrm{Fe}, \mathrm{Co})$ ingots were prepared by arc melting pure metals under argon atmosphere in a water cooled $\mathrm{Cu}$ crucible. The ingots were melted several times for homogeneity and encapsulated under vacuum in quartz glass. They were then annealed at $1073 \mathrm{~K}$ for 72 hours to achieve a high degree of atomic order. Finally, the samples were quenched in ice-water. The compositions of the alloys were determined by energy dispersive x-ray photoluminescence analysis (EDX) with an estimated error less than $\pm 0.3 \%$. Results are collected in Table 1. The reference system was nearly stoichiometric $\mathrm{Ni}_{2} \mathrm{MnGa}$, which shows a high temperature L2 $2_{1}$ structure $(F m 3 m)$.

The alloys were grouped according to their compositions into three different families for each of the doping elements:

(1) Fe substitution:

- $\mathrm{Ni}_{52.5-x} \mathrm{Mn}_{23} \mathrm{Ga}_{24.5} \mathrm{Fe}_{x}(0 \leq x \leq 5.2)$, for which $\mathrm{Ni}$ is replaced by Fe. - $\mathrm{Ni}_{52.5} \mathrm{Mn}_{22.3-x} \mathrm{Ga}_{25.2} \mathrm{Fe}_{x}(0 \leq x \leq 5.2)$, for which $\mathrm{Mn}$ is replaced by Fe. - $\mathrm{Ni}_{52.7} \mathrm{Mn}_{22.1} \mathrm{Ga}_{25.2-x} \mathrm{Fe}_{x}(0 \leq x \leq 5.3)$, for which Fe replaces Ga.

(2) Co substitution:

- $\mathrm{Ni}_{50.9-x} \mathrm{Mn}_{24.6} \mathrm{Ga}_{24.5} \mathrm{Co}_{x}(0 \leq x \leq 5.2)$, for which $\mathrm{Ni}$ is replaced by Co. - $\mathrm{Ni}_{50.6} \mathrm{Mn}_{25-x} \mathrm{Ga}_{24.4} \mathrm{Co}_{x}(0 \leq x \leq 5.1)$, for which $\mathrm{Mn}$ is replaced by Co.

- $\mathrm{Ni}_{50.6} \mathrm{Mn}_{24.4} \mathrm{Ga}_{25-x} \mathrm{Co}_{x}(0 \leq x \leq 6.4)$, for which Co replaces Ga.

Structural transition temperatures were obtained from ac susceptibility and calorimetric measurements. Specimens cut from the ingots using a low speed diamond saw (typical size $5 \times 1 \times 1 \mathrm{~mm}^{3}$ ) were used as samples for susceptibility and calorimetric studies. Magnetic susceptibility measurements were carried out in an ac susceptometer (LakeShore 7120A) in the temperature range $80 \mathrm{~K} \leq T \leq 320 \mathrm{~K}$. The working parameters were $500 \mathrm{~A} \mathrm{~m}^{-1}(6.28 \mathrm{Oe})$ applied field and $375 \mathrm{~Hz}$ frequency. For differential scanning calorimetry (DSC) measurements, one side of the samples was ground with $\mathrm{SiC}$ abrasive to ensure optimal thermal contact. Calorimetric measurements were carried out by means of a high sensitivity calorimeter in the temperature range $100 \mathrm{~K} \leq T \leq 350 \mathrm{~K}$. Typical heating and cooling rates were $2 \mathrm{~K} \mathrm{~min}^{-1}$. Magnetic transition temperatures were determined by means of a DSC calorimeter TA 2920 suitable for higher temperatures. All transition temperatures are affected by an error of $\pm 1 \mathrm{~K}$. We also determined the entropy change associated with the martensitic transition from calorimetric measurements. The errors in entropy change are based on reproducibility and shown as errors bars in the figures.

Temperature dependent structural analysis were carried out with a Siemens D500 x-ray diffractometer $\left(\mathrm{Cu} K_{\alpha}\right.$ radiation) equipped with a low temperature stage.

\section{Results}

In this section, we present representative results of susceptibility and calorimetric measurements for each family and doping element. These selected results illustrate the evolution of the magnetic and structural properties with each of the $3 d$ substituted elements. From the complete set of data we determine a phase diagram for each family and doping element and the transition entropy change at the martensitic transformation. 


\subsection{Ni substitution}

Figure 1(a) shows the ac susceptibility curves for selected samples of the family which results when replacing Ni by Co. For the undoped sample $(x=0)$, susceptibility measurements reveal the presence of a martensitic transformation. The corresponding transition temperatures are: martensite start temperature $M_{s}=216 \mathrm{~K}$, martensite finish temperature $M_{f}=203 \mathrm{~K}$, austenite start temperature $A_{s}=215$ $\mathrm{K}$ and austenite finish temperature $A_{f}=226 \mathrm{~K}$. The Curie point was determined from complementary DSC measurements as $T_{C}=374 \mathrm{~K}$. In addition to the martensitic transformation, an extra feature is observed in the susceptibility curve at temperatures above the martensitic transition which is associated with the formation of the intermediate or premartensitic phase $[19,24]$. The transition temperature is $T_{I}=256 \mathrm{~K}$. As can be seen from the figure, when increasing the amount of Co concentration both premartensitic and martensitic transition temperatures are displaced to lower temperatures and eventually both transitions merge. This behaviour is illustrated by sample $x=2.6$; for this sample, the features associated with both structural transformations are close to each other and are difficult to distinguish. Here, calorimetric measurements reveal crucial to discern both transitions. Figure 1(b) shows the calorimetric curves for this sample recorded on cooling and heating. At low temperatures, the martensitic transition is revealed by multiple peaks which are consequence of the well-known jerky character of martensitic transformations. The presence of the premartensitic transition is revealed by an additional feature observed in the calorimetric curves at temperatures above the martensitic transition, magnified in the inset of Figure 1(b) for the sake of clarity.

Analogously, Figure 2 shows the ac susceptibility and calorimetric curves for selected samples of the corresponding family when substituting Fe. Note that the $x=0$ samples for the Fe-doped and Co-doped alloys have different compositions. In this case, for the undoped sample $\left(T_{C}=351 \mathrm{~K}\right)$, susceptibility measurements reveal the presence of a martensitic transformation on cooling at $M_{s}=291 \mathrm{~K}$ and $M_{f}=272 \mathrm{~K}$. On heating, the reverse transformation takes place at $A_{s}=274 \mathrm{~K}$ and $A_{f}=295 \mathrm{~K}$. At lower temperatures, there is another distinct structural transformation, namely, the intermartensitic transformation, occurring at $T_{I M}=211$ $\mathrm{K}$ during cooling and at $239 \mathrm{~K}$ during heating with a temperature hysteresis of $\sim 40 \mathrm{~K}$ (estimated as the temperature difference at half intermartensitic transformation). The presence of such intermartensitic transformation was confirmed by the calorimetric measurements shown in Figure 2(b). The intermartensitic transformation was first observed in Ni-Mn-Ga in some prestressed [30, 31] and Mn-rich [27] samples . However, these transformations were non-thermoelastic, only occurring while cooling. Clearly, our observed intermartensitic transformation shows a complete thermoelastic behaviour. Thermoelastic intermartensitic transitions have been reported previously for Ni-Mn-Ga samples within a narrow composition range with $e / a$ values close to 7.6 [18, 28, 29, 32, 33]. More details of the intermartensitic transition will be given in next section.

Figure 3 summarizes the results obtained when substituting $\mathrm{Ni}$ by $\mathrm{Co}$ and $\mathrm{Fe}$ $3 d$ elements. Figure 3(a) shows the dependence of the transition temperatures as a function of Co concentration. It should be noted that all of the transition temperatures associated with the martensitic transformation $\left(M_{s}, M_{f}, A_{s}\right.$ and $\left.A_{f}\right)$ follow similar $x$ dependence. Thus, for the sake of clarity only $M_{s}$ temperatures are plotted. As can be seen from that figure, the martensitic transformation temperatures decrease as the amount of Co increases. In ternary Ni-Mn- $Z$ systems (where $Z$ is $\mathrm{Ga}, \mathrm{Al}, \mathrm{Sn}, \mathrm{In}$, and $\mathrm{Sb}$ ), it is well established that martensitic transformation temperatures decrease as the valence electron concentration $e / a$ decreases $[3,4,47-50]$. When replacing $\mathrm{Ni}\left(3 d^{8} 4 s^{2}\right)$ by Co $\left(3 d^{7} 4 s^{2}\right), e / a$ decreases and a drop 
in $M_{s}$ is expected. This behaviour is seen in Figure 3(a). Premartensitic transformation temperatures also decrease as the Co concentration increases but at higher rate than $M_{s}$. Thus, when increasing Co concentration both structural transition temperatures $M_{s}$ and $T_{I}$ get closer and eventually meet. Note that transition temperatures for the $x=5.2$ sample are in the limit of the temperature range which was accessible in our experiments. For this sample we did not observe the martensitic transition and we were only able to determine unequivocally the premartensitic transition temperature. It should be mentioned that Cong et al. observed an abrupt decrease of martensitic transition temperatures in $\mathrm{Ni}_{53-x} \mathrm{Mn}_{25} \mathrm{Ga}_{22} \mathrm{Co}_{x}$ for compositions $x>6$, which was attributed to atomic disorder caused by the addition of large amounts of Co [51]. Atomic disorder leads to a substantial suppression of the martensitic transition temperatures also in $\mathrm{Ni}_{2} \mathrm{MnGa}$ [52]. All these facts are illustrated by the dashed line in Figure 3(a). We note that for Co doping, $T_{C}$ increases proportionally with $x$.

On the other hand, Figure 3(b) shows the transition temperatures as a function of $\mathrm{Fe}$ content for the (Ni,Fe) alloy family. Again, all transition temperatures associated with the martensitic transformation follow the same $x$ dependence and thus only $M_{s}$ are included. The same criterion was applied to the intermartensitic transformation and only $T_{I M}$ are shown. Again, the martensitic transformation temperatures decrease as the amount of Fe increases $\left[e / a\right.$ decreases; Ni $\left(3 d^{8} 4 s^{2}\right)$ and $\mathrm{Fe}\left(3 d^{6} 4 s^{2}\right)$ ], consistently with the behaviour of ternary Ni-Mn- $Z$ alloys and the samples with Co substitution. Premartensitic transformation temperatures decrease as the $\mathrm{Fe}$ concentration increases as well but, in this case, at a lower rate than $M_{s}$. Thus, when increasing Fe concentration both structural transition temperatures $M_{s}$ and $T_{I}$ move apart each other. Such behaviour is opposite to the one observed when substituting Co. Furthermore, the temperature of the ferromagnetic transition $T_{C}$ increases with increasing $x$, as in the case of Co substitution.

Figure 4 shows the entropy change at the martensitic transformation as a function of the doping concentration for both $\mathrm{Fe}$ and Co addition. The concentration dependence of $\Delta S$ is similar to the behavior of $M_{s}$ for both systems, i.e., the entropy change decreases as the amount of doping increases. Such a dependence reflects the stabilization of the cubic phase with increasing doping concentration.

\section{2. $\quad$ Mn substitution}

Figures 5(a) and (b) illustrate typical results obtained when replacing $\mathrm{Mn}$ by $\mathrm{Fe}$ and Co, respectively. Figure 5(a) shows the ac susceptibility curves for selected samples of the $(\mathrm{Mn}, \mathrm{Fe})$ family. As can be seen from that figure, when increasing the amount of $\mathrm{Fe}$ concentration both martensitic and intermartensitic transitions shift to lower temperatures. The presence of the intermartensitic transformation undergone by these samples was again confirmed by calorimetric measurements, as illustrated in the inset of Figure 5(a). On the other hand, Figure 5(b) shows the ac susceptibility curves for selected samples of the corresponding (Mn,Co) family. In this case, the samples show a rich behaviour when adding Co. While the undoped sample shows a premartensitic transition at $T_{I}=256 \mathrm{~K}$ followed by a martensitic transformation at lower temperatures, $M_{s}=216 \mathrm{~K}$, the doped $x=2.1$ sample undergoes a martensitic transformation at $M_{s}=246 \mathrm{~K}$ followed by an intermartensitic transition at lower temperatures, $T_{I M}=159 \mathrm{~K}$. In the latter sample no signatures of the premartensitic transformation were observed. As follows from the present results, these alloys transform from the parent phase to a final martensitic structure through a thermally induced intermartensitic transformation. These transformations occur both while cooling and heating, thus showing thermoelastic 
behaviour. The small value of the intermartensitic transformation latent heat compared to the one associated with the martensitic transformation (note the large size change of the calorimetric peaks associated with martensitic and intermartensitic transformations in Figures 2 and 5) illustrates the closeness of the free energies of the different martensites.

In order to confirm the presence of the intermartensitic transition in the studied samples, we carried out x-ray diffraction measurements at several temperatures across the martensitic and the intermartensitic phase transitions for one specimen. These results enabled determination of the structure of the different martensitic phases. Figure 6 shows the x-ray diffraction patterns taken at $145 \mathrm{~K}$ and $270 \mathrm{~K}$ while heating for the $\mathrm{Ni}_{52.5} \mathrm{Mn}_{20.1} \mathrm{Ga}_{25.1} \mathrm{Fe}_{2.3}$ sample. Prior to the measurements, the sample was cooled down to $\sim 130 \mathrm{~K}$, i.e., below the intermartensitic phase transition $\left(T_{I M}\right)$. Such a sequence ensures that the sample fully transforms to the intermartensitic phase before the measurements take place. All the intense peaks have been indexed and labelled in Figure 6. At low temperatures, the martensite shows a monoclinic modulated $14 M$ structure with lattice parameters $a=0.424$ $\mathrm{nm}, b=0.547 \mathrm{~nm}$ and $c=2.937 \mathrm{~nm}$, with $\beta=94.3^{\circ}$ [Figure 6(a)]. When the temperature is increased, the diffraction pattern changes clearly indicating the existence of the reverse intermartensitic transition. The corresponding structure is (slightly) monoclinic modulated $10 M$ with lattice parameters $a=0.418 \mathrm{~nm}$, $b=0.554 \mathrm{~nm}$ and $c=2.106 \mathrm{~nm}$, with $\beta=90.3^{\circ}$ [Figure $\left.6(\mathrm{~b})\right]$. The present sequence of intermartensitic transitions is $14 M \rightarrow 10 M \rightarrow P$ while heating. Such sequence is in agreement with previously stress [30,31] and thermal induced [27,33] intermartensitic transitions. In the present experiments, however, a second intermartensitic transition to a low temperature non-modulated phase was not observed [33]. Such behaviour can be ascribed to the fact that intermartensitic transitions are very sensitive to internal stresses present in the samples [28, 33] and this can lead to differences in the particular intermartensitic transition sequence observed $[18,28,29,32,33]$.

The variation of transition temperatures with both Co and Fe concentration for these families are collected in Figures 7(a) and (b), respectively. Several interesting features come up from these phase diagrams. As can be seen from Figure 7(a), $M_{s}$ increases when increasing the amount of Co concentration, as expected due to the increase of $e / a$ when replacing $\mathrm{Mn}\left(3 d^{5} 4 s^{2}\right)$ by Co $\left(3 d^{7} 4 s^{2}\right)$. On the other hand, both premartensitic $T_{I}$ and intermartensitic $T_{I M}$ transition temperatures decrease with increasing the doping concentration and $T_{C}$ slightly increases with $x$. From our data, it appears that only when the premartensitic transition disappears, i.e., meets the martensitic transformation, the intermartensitic transformation develops. In fact, this was also pointed out in the phase diagram plotted in Figure 3(b) for the quaternary Ni-Mn-Ga-Fe. This behaviour seems to be intimately related to the mechanisms of the structural transitions. Indeed, the appearance of the different structural phases is related to the anomalous instability of the crystal lattice with respect to atomic displacements of $\{110\}$ planes along $\langle 1 \overline{1} 0\rangle$ directions and manifests in different modulations of stacking planes in such directions.

Figure 7(b) shows the dependence of the transition temperatures on the amount of Fe substitution. Here, the martensitic transition temperature decreases when increasing Fe concentration, i.e., increasing $e / a$. This behaviour is unexpected from the scaling of the martensitic transition temperatures with the electronic concentration. However, our present results agree with those reported in most of the literature $[35,39,44]$. Interestingly, a similar behaviour has been recently reported in Ni-Mn-Sn alloys: while a decrease of martensitic transition temperatures when increasing $e / a$ has been observed when replacing Mn by Fe [53], an increase of the 
transition temperatures with increasing the electron per atom concentration has been reported when substituting $\mathrm{Ni}$ by $\mathrm{Fe}$ [54]. These results indicate that other parameters than $e / a$ affect phase stability. In particular, our results suggest that magnetic interactions play an important role. The intermartensitic transformation temperatures behave in a similar way and also decrease with increasing Fe content. No intermartensitic transformations were detected for Fe substitution higher than $\sim 4 \%$, as illustrated by the dashed line. It should be noted that a decrease of thermoelastic intermartensitic transformation temperatures with the electron concentration has also been previously reported in Ni-Mn-Fe-Cu-Ga system [55]. Moreover, the Curie point increases with $x$.

Figure 8 shows the dependence of the entropy change at the martensitic transformation on the amount of $\mathrm{Fe}$ and Co addition. As can be seen from that figure, $3 d$ element substitution does not substantially modify the values of the entropy change at the martensitic transition when replacing Mn by Fe and/or Co. It should be mentioned that it was not possible to evaluate properly $\Delta S$ for the (Mn,Co) $x=5.1$ sample due to the broadening of the martensitic transition and therefore this value is not included in the plot.

\subsection{Ga substitution}

Finally, we discuss the results obtained for the (Ga,Fe) and (Ga,Co) families. Figure 9 shows calorimetric curves for selected samples from each family. In this case, due to the high values of the transformation temperatures only calorimetric data are discussed. As can be seen from that figure, martensitic transformation temperatures strongly increase when substituting both $3 d$ doping elements. This is clearly seen in Figure 10, where we plotted the phase diagrams of these two families. Such strong $x$ dependence is consistent with the rapid increase of $e / a$ when Fe and/or Co are substituted for $\mathrm{Ga}\left[\mathrm{Ga}\left(4 s^{2} 4 p^{1}\right)\right.$, Fe $\left(3 d^{6} 4 s^{2}\right)$ and $\left.\mathrm{Co}\left(3 d^{7} 4 s^{2}\right)\right]$. By contrast, the Curie point shows a different behaviour as a function of $x$ for each family. On the one hand, in the Co doped samples the Curie point is almost independent of the doping concentration when the ferromagnetic transition takes place in the austenitic state, while $T_{C}$ decreases with increasing $x$ when the ferromagnetic transition occurs within the martensitic state. On the other hand, for the $(\mathrm{Ga}, \mathrm{Fe})$ samples $T_{C}$ increases with increasing doping concentration over the entire studied range, the slope of the increase being larger when the martensitic and the ferromagnetic transition meet each other. This behaviour is ascribed to the coupling between the magnetic and the structural transitions and the significant increase of $M_{s}$ with $x$ [56] and has been previously observed in Ga substituted for Ni and Mn ternary alloys [57-59]. Finally, notice that no signatures of either premartensitic or intermartensitic transitions were observed in these families.

The entropy change at the martensitic transition as a function of $\mathrm{Fe}$ and $\mathrm{Co}$ concentration is collected in Figure 11. As can be seen from this figure, $\Delta S$ parallels the behaviour of the martensitic transformation temperatures and increases as the amount of doping increases, pointing out the stabilization of the the low temperature phase due to $\mathrm{Fe}$ and Co substitution.

\section{Discussion}

In this paper we have studied the effect of $\mathrm{Fe}$ and Co $3 d$ elements substitution on the relative phase stability of the prototypical magnetic shape memory alloy Ni-Mn-Ga for compositions close to the 2-1-1 stoichiometry. An effort was made 
to selectively substitute each constituent element by same amounts of doping. In this way, we were able to systematically study the effect of substitution at a particular site for each doping element. The complete set of results for magnetic and structural transition temperatures obtained from calorimetric and ac-susceptibility measurements are shown as a function of the electron concentration $e / a$ in Fig. 12. This representation shows that $e / a$ is a convenient parameter for reducing both magnetic and structural transition temperatures and confirms that phase stability in shape-memory Heusler materials is controlled by electronic degrees of freedom to a large extent $[47,48]$. However, the scatter of the data points which is higher than that observed in the phase diagrams corresponding to the three studied composition related families (see Figs. 3, 7 and 10) already suggests that additional parameters other than electron concentration affect phase stability. In this sense, it is known that the ground state of Ni-Mn- $Z$ alloys ( $Z$ as $\mathrm{Ga}, \mathrm{In}, \mathrm{Al}, \ldots)$ shows the same sequence of phases when $e / a$ is increased [50]. However, for a given value of $e / a$ the corresponding $M_{s}$ transition temperature displays a strong dependence on the $Z$ element $[4,61]$. Khan et al. [62] specifically studied the effect of isoelectronic substitution of Ga by In in $\mathrm{Ni}_{2} \mathrm{MnGa}$ and concluded that the effect of $Z$ on $M_{s}$ mainly arise from the change of unit cell volume which modifies the relative position of the Brillouin zone boundary and Fermi surfaces. The role of volume effects on the martensitic transition has been further studied via doping of Ni-Mn-Ga with several other elements and use of electron density to parametrize structural transition temperatures has been suggested [63, 64]. The effect of magnetism on the martensitic transition, however, has been studied in less detail. Recently, Roy et al. [65] have shown that substitution of $\mathrm{Mn}$ by non-magnetic $\mathrm{Cu}$ has considerable influence on phase stability. $\mathrm{Cu}$ gives rise to delocalization of the $\mathrm{Mn}$ magnetism which is accompanied by an increase of Ni-covalency and a reinforcement of the $\mathrm{Ni}-\mathrm{Ga}$ bonds [65]. The result in this case is a decrease of the Curie temperature and an increase of stability of the martensitic phase with respect to the parent compound.

In order to compare our present results for Fe- and Co-doped alloys to the behaviour of the ternary system, the phase diagram of Ni-Mn-Ga is indicated in Fig. 12 by dashed lines. Such comparison is useful to obtain information about the effect of magnetism on the structural transitions due to our selection of doping atoms with similar atomic radii but different magnetic properties. The general trends of all three systems are similar: $M_{s}$ and $T_{I}$ increase as $e / a$ increases, whereas $T_{I M}$ and $T_{C}$ decrease. Notice that for intermartensitic transitions, only data belonging to thermoelastic transformations have been taken into account. In the case of the Fe substituted system, at constant $e / a$, we find that the addition of Fe to Ni-MnGa shifts the structural transition temperatures $M_{s}, T_{I}$ and $T_{I M}$ to lower values, whereas $T_{C}$ shifts to higher temperatures. On the other hand, when Co is added to the ternary system the effect of doping on the phase transition temperatures is more complex. While for low values of $e / a M_{s}$ are displaced to lower values, for higher $e / a$ the martensitic transition temperatures are shifted to higher values. Additionally, $M_{s}$ and $T_{I}$ are suppressed for values of $e / a \lesssim 7.50$. Such behaviour differs from the linearity observed in both ternary and Ni-Mn-Ga-Fe systems. As mentioned before, Cong et al. observed an abrupt decrease of the martensitic transition temperature in Co-doped systems, which was attributed to atomic disorder caused by the addition of large amounts of Co [51]. However, from the comparison of both quaternary compounds, it can be seen that the Fe-doped system does not show such a dramatic suppression of $M_{s}$ and $T_{I}$ for similar amounts of doping (and thus similar $e / a$ values). Due to the similar atomic radii and concentration of doping atoms considered, the differences between both quaternary systems observed 
here should be ascribed to the different magnetic properties of Fe and Co. Notice that the Curie temperatures values for these Co-doped samples are significantly higher than the corresponding $T_{C}$ values for the Fe-doped samples, which suggests that the strengthening of the magnetic interactions stabilizes the austenitic phase. This behaviour is in agreement with the rapid decrease of $M_{s}$ accompanied by considerable increase of $T_{C}$ observed in the results from Cong et al. [51] and also in recent results from Kanomata and co-workers [68]. On the other hand, the scarce $T_{I M}$ data does not allow a detailed determination of the effect of Co addition on the intermartensitic transformation, although from comparison with both ternary and Fe-doped systems one expects $T_{I M}$ to decrease when increasing $e / a$. Regarding the Curie point, $T_{C}$ shifts to higher values when the magnetic transition occurs within the austenitic state (low $e / a$ ), while it is slightly displaced to lower values when takes place within the martensitic state (high $e / a$ values).

Preceding results indicate that in both Fe- and Co-doped Ni-Mn-Ga alloys, magnetic effects play a certain role in controlling relative phase stability. In the region where the martensitic transition occurs in the ferromagnetic phase below the Curie point, the increase of $T_{C}$ with respect to Ni-Mn-Ga suggests that both Feand Co-addition give rise to a strengthening of magnetic exchange coupling and this seems to be responsible for lowering structural transition temperatures. Additional information on the effect of magnetism on the martensitic transition can be obtained from the $e / a$ dependence of the entropy difference $\Delta S$ between the high temperature cubic phase and the low temperature martensitic phase. Due to the diffusionless nature of the martensitic transition, the distribution of atoms in the parent phase is inherited by the martensitic phase and $\Delta S$ should only contain vibrational, electronic and magnetic contributions. Fig. 13 shows the entropy change at the martensitic transformation as a function of electron concentration per atom $e / a$ for (a) Ni-Mn-Ga-Fe and (b) Ni-Mn-Ga-Co systems. Like in the ternary Ni-Mn-Ga, in both quaternary systems $\Delta S$ increases as the electron per atom concentration increases. In the case of Ni-Mn-Ga, the large concentration dependence of the entropy change was attributed by Khovailo et al. to changes of the magnetic contributions [67]. Actually, when the martensitic transition occurs above the Curie point, the magnetic contribution to the entropy change should be very small and the entropy change is expected to be largely provided by the lattice vibrational contribution. In contrast, when the transition occurs below the Curie temperature a magnetic contribution to the entropy of opposite sign to the vibrational contribution is expected. This magnetic contribution is responsible for the increase of $\Delta S$ with increasing $e / a$. In the case of Fe and Co substituted alloys the entropy changes for a given value of $e / a$ are lower than those in the corresponding ternary Ni-Mn-Ga system. This drop confirms the suggested strengthening of magnetic exchange coupling when adding $\mathrm{Fe}$ and $\mathrm{Co}$ which results in a decrease of the free energy difference between the parent and martensite phases when the alloy orders magnetically [34], and therefore stabilization of the high temperature phase. The reduction of entropy change at a given electron concentration is considerably larger in Co-doped alloys which means that Co has a stronger effect on magnetic exchange coupling than Fe. Such stronger effect is consistent with the abrupt decrease of martensitic (and premartensitic) transition temperatures shown in Figure 12(b), and further indicates that the strengthening of magnetic interactions stabilizes the high temperature cubic phase. 


\section{Conclusions}

We studied the effect of $\mathrm{Fe}$ and Co selective substitution on the magnetic and structural phase transitions exhibited by Ni-Mn-Ga alloys. We determined the phase diagrams and the entropy changes at the martensitic transition of the resulting quaternary systems. Similarities between ternary Ni-Mn-Ga and quaternary NiMn-Ga-Fe and Ni-Mn-Ga-Co systems reaffirm that electronic concentration qualitatively controls phase stability in these compounds. However, differences between these systems show that additional parameters affect phase stability and therefore $e / a$ can only be used for examining systematic changes of structural and magnetic properties within a single-alloy system. In particular, differences between both quaternary systems indicate that relative phase stability is strongly modified by the strengthening of magnetic exchange coupling induced by Fe- and Co-doping and evidence that magnetic interactions affect the structural and magnetic phase transitions exhibited by Heusler magnetic shape memory alloys.

\section{Acknowledgement(s)}

This work received financial support from the CICyT (Spain), Project No. MAT2007-61200, and from CONACYT (44786-SEP-CONACYT 2003). X. M. acknowledges support from Comissionat per a Universitats i Recerca (CUR) del Departament d'Innovació, Universitats i Empresa de la Generalitat de Catalunya.

\section{References}

[1] O. Söderberg, A. Sozinov, Y. Ge, S.-P. Hannula and V. K. Lindroos, Handboof of Magnetic Materials, Vol. 16, edited by J. Buschow, Elsevier Science, Amsterdam (2006).

[2] Y. Sutou, Y. Imano, N. Koeda, T. Omori, R. Kainuma, K. Ishida and K. Oikawa, Appl. Phys. Lett. $85(2004)$ p. 4358.

[3] T. Krenke, M. Acet, E. F. Wassermann, X. Moya, L. Mañosa and A. Planes Phys. Rev. B 72 (2005) p. 014412.

[4] T. Krenke, M. Acet, E. F. Wassermann, X. Moya, L. Mañosa and A. Planes, Phys. Rev. B 73 (2006) p. 174413.

[5] K. Ullakko, J. K. Huang, C. Kantner, R. C. O'Handley and V.V. Kokorin, Appl. Phys. Lett. 69 (1996) p. 1966.

[6] R. Kainuma, Y. Imano, W. Ito, , Y. Imano, W. Ito, Y. Sutou, H. Morito, S. Okamoto, O. Kitakami, K. Oikawa, A. Fujita, T. Kanomata and K. Ishida, Nature 439 (2006) p. 957.

[7] T. Krenke, E. Duman, M. Acet, E. F. Wassermann, X. Moya, L. Mañosa, A. Planes, E. Suard and B. Ouladdiaf, Phys. Rev. B 75 (2007) p. 104414.

[8] C. Biswas, R. Rawat and S. R. Barman, Appl. Phys. Lett. 86 (2005) p. 202508.

[9] K. Koyama, H. Okada, K. Watanabe, T. Kanomata, W. Ito, K. Oikawa and R. Kainuma, Appl. Phys. Lett. 89 (2006) p. 182510.

[10] V. K. Sharma, M. K. Chattopadhyay, K. H. B. Shaeb, A. Chouhan and S. B. Roy, Appl. Phys. Lett. 89 (2006) p. 222509.

[11] F. Hu, B. Shen and J. Sun, Appl. Phys. Lett. 76 (2000) p. 3460.

[12] J. Marcos, A. Planes, L. Mañosa, F. Casanova, X. Batlle, A. Labarta and B. Martínez, Phys. Rev. B 66 (2002) p. 224413.

[13] T. Krenke, E. Duman, M. Acet, E. F. Wassermann, X. Moya, L. Mañosa and A. Planes, Nature Materials 4 (2005) p. 450.

[14] X. Moya, L. Mañosa, A. Planes, T. Krenke, E. Duman, M. Acet and E. F. Wassermann, J. Magn. Magn. Mater. 316 (2007) p. e572.

[15] Z. D. Han, D. H. Wang, C. L. Zhang, S. L. Tang, B. X. Gu and Y. W. Du, Appl. Phys. Lett. 89 (2006) p. 182507.

[16] X. Moya, L. Mañosa, A. Planes, S. Aksoy, T. Krenke, M. Acet and E. F. Wassermann, Phys. Rev. B 75 (2007) p. 184412.

[17] A. Planes, L. Mañosa and M. Acet, J. Phys.: Condens. Matter 21 (2009) p. 233201.

[18] A. Sozinov, A. A. Likhachev, N. Lanska and K. Ullakko, Appl. Phys. Lett. 80 (2002) p. 1746.

[19] A. Planes, E. Obradó, A. Gonzàlez-Comas and L. Mañosa, Phys. Rev. Lett.79 (1997) p. 3926.

[20] A. Zheludev, S. M. Shapiro, P. Wochner, A. Schwartz, M. Wall and L. E. Tanner, Phys. Rev. B 51 (1995) p. 11310.

[21] A. Zheludev, S. M. Shapiro, P. Wochner and L. E. Tanner, Phys. Rev. B 54 (1996) p. 15045. 
[22] L. Mañosa, A. Planes, J. Zarestky, T. Lograsso, D. L. Schlagel and C. Stassis, Phys. Rev. B 64 (2001) p. 024305 .

[23] J. Worgull, E. Petti and J. Trivisonno, Phys. Rev. B 54 (1996) p. 15695.

[24] L. Mañosa, A. Gonzàlez-Comas, E. Obradó, A. Planes, V. A. Chernenko, V. V. Kokorin and E. Cesari, Phys. Rev. B 55 (1997) p. 11068.

[25] M. Stipcich, L. Mañosa, A. Planes, M. Morin, J. Zarestky, T. Lograsso and C. Stassis, Phys. Rev. B $70(2004)$ p. 054115.

[26] C. P. Opeil, B. Mihaila, R. K. Schulze, L. Mañosa, A. Planes, W. L. Hults, R. A. Fisher, P. S. Riseborough, P. B. Littlewood, J. L. Smith and J. C. Lashley, Phys. Rev. Lett. 100 (2008) p. 165703.

[27] V. A. Chernenko, C. Segui, E. Cesari, J. Pons and V. V. Kokorin, Phys. Rev. B 57 (1998) p. 2659.

[28] W. H. Wang, Z. H. Liu, J. Zhang, J. L. Chen, G. H. Wu, W. S. Zhan, T. S. Chin, G. H. Wen and X. X. Zhang, Phys. Rev. B 66 (2002) p. 052411.

[29] W. H. Wang, G. H. Wu, J. L. Chen, S. X. Gao, W. S. Zhan, G. H. Wen and X. X. Zhang, Appl. Phys. Lett 79 (2001) p. 1148.

[30] V. V. Martynov and V. V. Kokorin, J. Physique III 2 (1992) p. 739.

[31] A. N. Vasil'ev, A. Kaiper, V. V. Kokorin, V. A. Chernenko, T. Takagi and J. Tani, JETP Lett. 58 (1993) p. 297.

[32] O. Heczko, N. Lanska, O. Soderberg and K. Ullako, J. Magn. Magn. Mater. 242-245 (2002) p. 1446.

[33] C. Seguí, V. A. Chernenko, J. Pons, E. Cesari, V. Khovailo and T. Takagi, Acta Mater. 53 (2005) p. 111.

[34] D. Soto, F. Alvarado-Hernández, H. Flores-Zúñiga, X. Moya, L. Mañosa, A, Planes, S. Aksoy, M. Acet and T. Krenke, Phys. Rev. B 77 (2008) p. 184103.

[35] Z. H. Liu, M. Zhang, W. Q. Wang, W. H. Wang, J. L. Chen and G. H. Wu, J. Appl. Phys. 92 (2002) p. 5006.

[36] V. V. Khovailo, T. Abe, V. V. Koledov, M. Matsumoto, H. Nakamura, R. Note, M. Ohtsuka, V. G. Shavrov and T. Takagi, Mater. Trans. 44 (2003) p. 2509.

[37] A. A. Cherechukin, T. Takagi, H. Miki, M. Matsumoto and M. Ohtsuka, J. Appl. Phys. 95 (2004) p. 1740.

[38] K. Koho, O. Söderberg, N. Lanska, Y. Ge, X. Liu, L. Straka, J. Vimpari, O. Heczko and V. K. Lindroos, Mater. Sci. Eng. A 378 (2004) p. 384

[39] D. Kikuchi, T. Kanomata, Y. Yamaguchi, H. Nishihara, K. Koyama and K. Watanabe, J. All. Comp. 383 (2004) p. 184.

[40] S. Guo, Y. Zhang, B. Quan, J. Li, Y. Qi and X. Wang, Smart Mater. Struct. 14 (2005) p. S236.

[41] M. Khan, I. Dubenko, S. Stadler and N. Ali, J. Appl. Phys. 97 (2005) p. 10M304.

[42] I. Glavatskyy, N. Glavatska, O. Soderberg, S. P. Hannula and J. U. Hoffmann, Scripta Mater. 54 (2006) p. 1891.

[43] M. Ohtsuka, M. Matsumoto, and K. Itagaki, Mater. Sci. Eng. A 438 (2006) p. 935.

[44] K. Tsuchiya, Y. Sho, T. Kushima, Y. Todaka and M. Umemoto, J. Magn. Magn. Mater. 310 (2007) p. 2764.

[45] V. Sánchez-Alarcos, J. I. Pérez-Landazábal and V. Recarte, Mater. Sci. Eng. A 481-482 (2008) p. 293.

[46] V. Sánchez-Alarcos, J. I. Pérez-Landazábal, V. Recarte, C. Gómez-Polo and J. A. RodríguezVelamazán, Acta Mater. 56 (2008) p. 5370.

[47] V. A. Chernenko, Scr. Mater. 40 (1999) p. 523.

[48] X. Jin, M. Marioni, D. Bono, S. M. Allen and R. C. O'Handley, J. Appl. Phys. 91 (2002) p. 8222

[49] M. Acet, E. Duman, E. F. Wassermann, L. Mañosa and A. Planes, J. Appl. Phys. 92 (2002) p. 3867.

[50] X. Moya, L. Mañosa, A. Planes, T. Krenke, M. Acet and E. F. Wassermann, Mater. Sci. Engn. A 438-440 (2006) p. 911.

[51] D. Y. Cong, S. Wang, Y. D. Wang, Y. Ren, L. Zuo and C. Esling, Mater. Sci. Engn. A 473 (2008) p. 213.

[52] M. Kreissl, K.-U. Neumann, T. Stephens and K. R. A. Ziebeck, J. Phys. Cond.: Matter 15 (2003) p. 3831.

[53] E. C. Passamani, F. Xavier, E. Favre-Nicolin, C. Larica, A. Y. Takeuchi, I. L. Castro and J. R. Proveti, J. Appl. Phys. 105 (2009) p. 033919.

[54] T. Krenke, E. Duman, M. Acet, X. Moya, L. Mañosa and A. Planes, J. Appl. Phys. 102 (2007) p. 033903.

[55] M. Khan, B. Gautam, A. Pathak, I. Dubenko, S. Stadler and N. Ali, J. Phys.: Condens. Matter 20 (2008) p. 505206.

[56] P. Entel, V. D. Buchelnikov, V. V. Khovailo, A. T. Zayak, W. A. Adeagbo, M. E. Gruner, H. C. Herper and E. F. Wassermann, J. Phys. D: Appl. Phys. 39 (2006) p. 865.

[57] C. Jiang, Y. Muhammad, L. Deng, W. Wu, and H. Xu, Acta Mater. 52 (2004) p. 2779.

[58] N. Lanska, O. Söderberg, A. Sozinov, Y. Ge, K. Ullako and V. K. Lindroos, J. Appl. Phys. 95 (2004) p. 8074.

[59] V. D. Buchelnikov, V. V. Khovailo, A. N. Vasilev and T. Takagi, J. Magn. Magn. Mater. 290-291 (2005) p. 854

[60] For Ni-Mn-Ga, data are compiled from a large number of papers. Original references are given in J. Marcos, PhD Thesis, Universitat de Barcelona, Barcelona, 2004.

[61] T. Krenke, X. Moya, S. Aksoy, M. Acet, P. Entel, L. Mañosa, A. Planes, Y. Elerman, A. Yücel and E. F. Wassermann, J. Magn. Magn. Mater. 310 (2007) p. 2788.

[62] M. Khan, I. Dubenko, S. Stadler and N. Ali, J. Phys.: Condens. Matter 16 (2004) p. 5259.

[63] X. Q. Chen, F. J. Yang, X. Lu and Z. X. Qin, Phys. Stat. Sol. (b) 244 (2007) p. 1047.

[64] X. Q. Chen, X. Lu, D. Y. Wang and Z. X. Qin, Smart Mater. Struct. 17 (2008) p. 065030.

[65] S. Roy, E. Blackburn, S. M. Valvidares, M. R. Fitzsimmons, S. C. Vogel, M. Khan, I. Dubenko, S. Stadler, N. Ali, S. K. Sinha and J. B. Kortright, Phys. Rev. B 79 (2009) p. 235127.

[66] V. A. Chernenko, E. Cesari, V. V. Kokorin and I. N. Vitenko, Scr. Metall. Mater. 33 (1995) p. 1239.

[67] V. V. Khovailo, K. Oikawa, T. Abe and T. Takagi, J. Appl. Phys. 93 (2003) p. 8483. 
1

2

3

4

5

6

7

8

9

10

11

12

13

14

15

16

17

18

19

20

21

22

23

24

25

26

27

28

29

30

31

32

33

34

35

36

37

38

39

40

41

42

43

44

45

46

47

48

49

50

51

52

53

54

55

56

57

58

59

60

[68] T. Kanomata, Y. Kitsunai, K. Sano, Y. Furutani, H. Nishihara,R. Y. Umetsu, R. Kainuma, Y. Miura and M. Shirai, Phys. Rev. B 80 (2009) p. 214402 
Table 1. Compositions of the Ni-Mn-Ga-Co and Ni-Mn-Ga-Fe samples determined by EDX. For each element doping, different specimens are grouped into three distinct families, depending on the element that is substituted (elements within parenthesis, first and seventh column, respectively). Samples displayed in the first row are the undoped reference Ni-Mn-Ga samples. The estimated

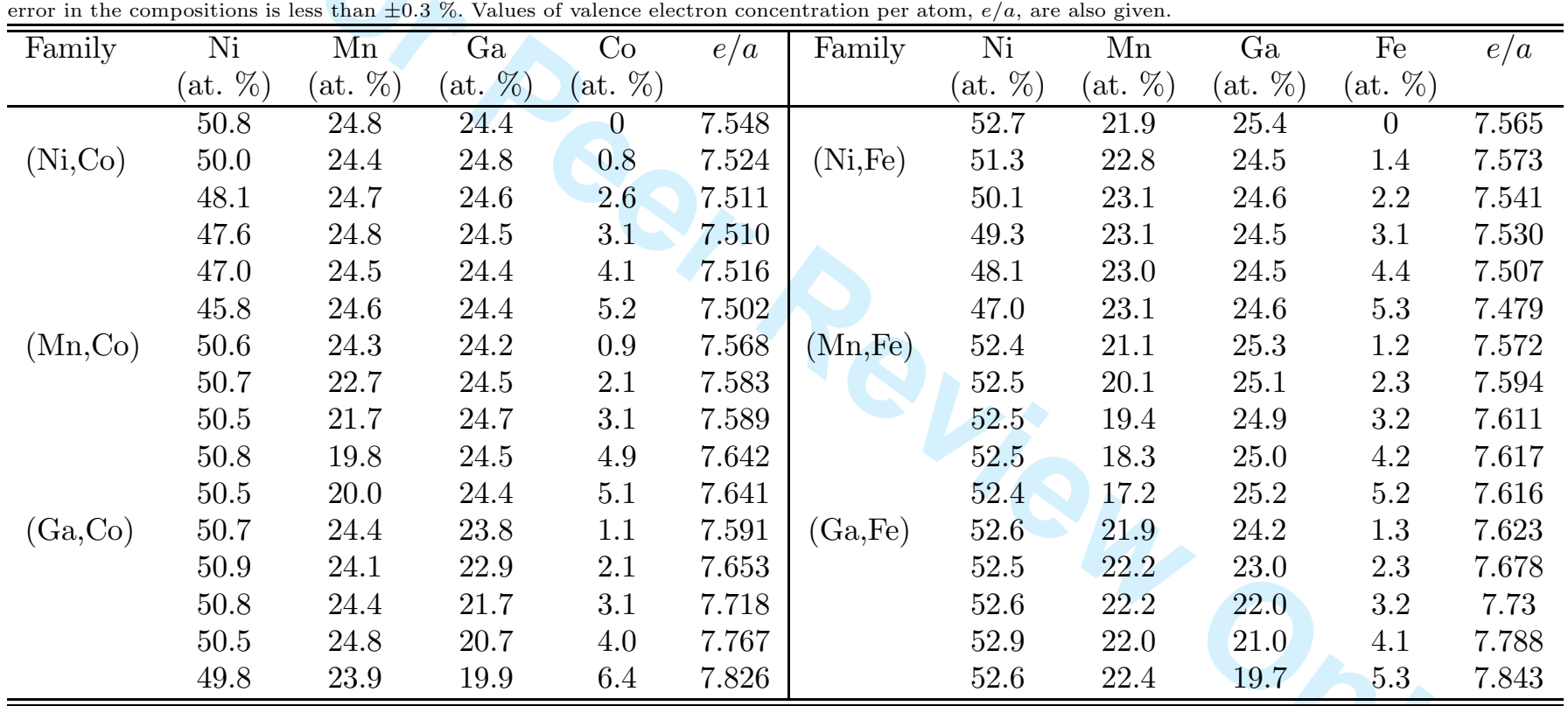


Figure 1. $\mathrm{Ni}_{50.9-x} \mathrm{Mn}_{24.6} \mathrm{Ga}_{24.5} \mathrm{Co}_{x}$ family. (a) Magnetic susceptibility versus temperature for samples of selected compositions. (b) Calorimetric curves for the sample with $x=2.6$ showing the martensitic and intermediate (magnified in the inset) transformations. Vertical arrows show the position of the premartensitic transition temperature, $T_{I}$. Horizontal arrows in panel (b) indicate direction of temperature change.

Figure 2. $\mathrm{Ni}_{52.5-x} \mathrm{Mn}_{23} \mathrm{Ga}_{24.5} \mathrm{Fe}_{x}$ family. (a) Magnetic susceptibility versus temperature for samples of selected compositions. (b) Calorimetric curves for the sample with $x=0$ showing the martensitic and intermartensitic (magnified in the inset) transformations. Vertical arrows in panel (a) show the position of the intermartensitic transition temperature, $T_{I M}$ (sample with $x=0$ ), and the premartensitic transition temperature, $T_{I}$ (samples with $x=1.4$ and 2.2). Horizontal arrows in panel (b) indicate direction of temperature change.

Figure 3. (a) Evolution of the transition temperatures of $\mathrm{Ni}_{50.9-x} \mathrm{Mn}_{24.6} \mathrm{Ga}_{24.5} \mathrm{Co}_{x}$ as a function of Co concentration. (b) Evolution of the transition temperatures of $\mathrm{Ni}_{52.5-x} \mathrm{Mn}_{23} \mathrm{Ga}_{24.5} \mathrm{Fe}_{x}$ as a function of Fe concentration. Lines are guides to the eye.

Figure 4. Entropy change at the martensitic transformation as a function of doping concentration ( $\mathrm{Fe}$ or $\mathrm{Co}$ ) for $\mathrm{Ni}$ substitution. Solid lines are linear fits to the experimental data.

Figure 5. (a) $\mathrm{Ni}_{52.5} \mathrm{Mn}_{22.3-x} \mathrm{Ga}_{25.2} \mathrm{Fe}_{x}$ family. Magnetic susceptibility versus temperature for samples of selected compositions. Inset illustrates the martensitic and the intermartensitic transformations for the sample $x=2.3$ detected by calorimetry. (b) $\mathrm{Ni}_{50.6} \mathrm{Mn}_{25-x} \mathrm{Ga}_{24.4} \mathrm{Co}_{x}$ family. Magnetic susceptibility versus temperature for selected samples. Vertical arrows show the position of the intermartensitic transition temperature, $T_{I M}$. Horizontal arrows in the inset of panel (a) indicate direction of temperature change.

Figure 6. X-ray diffraction patterns illustrating the change of the martensitic structure through the intermartensitic transition for the $\mathrm{Ni}_{52.5} \mathrm{Mn}_{20.1} \mathrm{Ga}_{25.1} \mathrm{Fe}_{2.3}$ sample. (a) Monoclinic $14 M$ structure $\left(T<T_{I M}\right)$ and (b) $10 M$ (slightly) monoclinic structure $\left(T<M_{s}\right)$.

Figure 7. (a) Evolution of the transition temperatures of $\mathrm{Ni}_{50.6} \mathrm{Mn}_{25-x} \mathrm{Ga}_{24.4} \mathrm{Co}_{x}$ as a function of Co concentration. (b) Evolution of the transition temperatures of $\mathrm{Ni}_{52.5} \mathrm{Mn}_{22.3-x} \mathrm{Ga}_{25.2} \mathrm{Fe}_{x}$ as a function of $\mathrm{Fe}$ concentration. Lines are guides to the eye.

Figure 8. Entropy change at the martensitic transformation as a function of doping concentration ( $\mathrm{Fe}$ or $\mathrm{Co}$ ) for $\mathrm{Mn}$ substitution. Solid lines are guides to the eye.

Figure 9. Calorimetric curves for samples of selected compositions of (a)-(b) $\quad \mathrm{Ni}_{52.7} \mathrm{Mn}_{22.1} \mathrm{Ga}_{25.2-x} \mathrm{Fe}_{x}$ and (c)-(d) $\mathrm{Ni}_{50.6} \mathrm{Mn}_{24.4} \mathrm{Ga}_{25-x} \mathrm{Co}_{x}$ families. Vertical arrows show the Curie point, $T_{C}$. Horizontal arrows indicate direction of temperature change. 
Figure 10. (a) Evolution of the transition temperatures of $\mathrm{Ni}_{50.6} \mathrm{Mn}_{24.4} \mathrm{Ga}_{25-x} \mathrm{Co}_{x}$ as a function of $\mathrm{Co}$ concentration. (b) Evolution of the transition temperatures of $\mathrm{Ni}_{52.7} \mathrm{Mn}_{22.1} \mathrm{Ga}_{25.2-x} \mathrm{Fe}_{x}$ as a function of Fe concentration. Solid lines are guides to the eye.

Figure 11. Entropy change at the martensitic transformation as a function of doping concentration ( $\mathrm{Fe}$ or $\mathrm{Co}$ ) for $\mathrm{Ga}$ substitution. Solid lines are guides to the eye.

Figure 12. (Color online) (a) Phase diagram of Ni-Mn-Ga-Fe system as a function of electron concentration per atom $e / a$. Filled symbols stand for $\mathrm{Ni}_{52.5-x} \mathrm{Mn}_{23} \mathrm{Ga}_{24.5} \mathrm{Fe}_{x}$ family; half-filled symbols stand for $\mathrm{Ni}_{52.5} \mathrm{Mn}_{22.3-x} \mathrm{Ga}_{25.2} \mathrm{Fe}_{x}$ family; open symbols stand for $\mathrm{Ni}_{52.7} \mathrm{Mn}_{22.1} \mathrm{Ga}_{25.2-x} \mathrm{Fe}_{x}$ family. (b) Phase diagram of Ni-Mn-GaCo system as a function of electron concentration per atom $e / a$. Filled symbols stand for $\mathrm{Ni}_{50.9-x} \mathrm{Mn}_{24.6} \mathrm{Ga}_{24.5} \mathrm{Co}_{x}$; half-filled symbols stand for $\mathrm{Ni}_{50.6} \mathrm{Mn}_{25-x} \mathrm{Ga}_{24.4} \mathrm{Co}_{x}$ family; open symbols stand for $\mathrm{Ni}_{50.6} \mathrm{Mn}_{24.4} \mathrm{Ga}_{25-x} \mathrm{Co}_{x}$ family. Lines are fits to the experimental data. Squares stand for $M_{s}$, circles stand for $T_{I}$, up and down triangles stand for $T_{C}$ and $T_{I M}$, respectively. Red dashed lines depict the (fitted) transition lines of the related Ni-Mn-Ga ternary system (data compiled from reference [60]). The open red circles stand for the thermoelastic intermartensitic transformation temperature in Ni-Mn-Ga [18, 29, 32, 33].

Figure 13. (Color online) (a) Entropy change at the martensitic transformation of Ni-Mn-Ga-Fe system as a function of electron concentration per atom $e / a$. Filled symbols stand for $\mathrm{Ni}_{52.5-x} \mathrm{Mn}_{23} \mathrm{Ga}_{24.5} \mathrm{Fe}_{x}$ family; half-filled symbols stand for $\mathrm{Ni}_{52.5} \mathrm{Mn}_{22.3-x} \mathrm{Ga}_{25.2} \mathrm{Fe}_{x}$ family; open symbols stand for $\mathrm{Ni}_{52.7} \mathrm{Mn}_{22.1} \mathrm{Ga}_{25.2-x} \mathrm{Fe}_{x}$ family. (b) Entropy change at the martensitic transformation of Ni-Mn-Ga-Co system as a function of electron concentration per atom $e / a$. Filled symbols stand for $\mathrm{Ni}_{50.9-x} \mathrm{Mn}_{24.6} \mathrm{Ga}_{24.5} \mathrm{Co}_{x}$; half-filled symbols stand for $\mathrm{Ni}_{50.6} \mathrm{Mn}_{25-x} \mathrm{Ga}_{24.4} \mathrm{Co}_{x}$ family; open symbols stand for $\mathrm{Ni}_{50.6} \mathrm{Mn}_{24.4} \mathrm{Ga}_{25-x} \mathrm{Co}_{x}$ family. Solid lines are linear fits to the experimental data. Red dashed lines depict the (fitted) entropy change of the related Ni-Mn-Ga ternary system (data compiled from references $[66,67])$. 

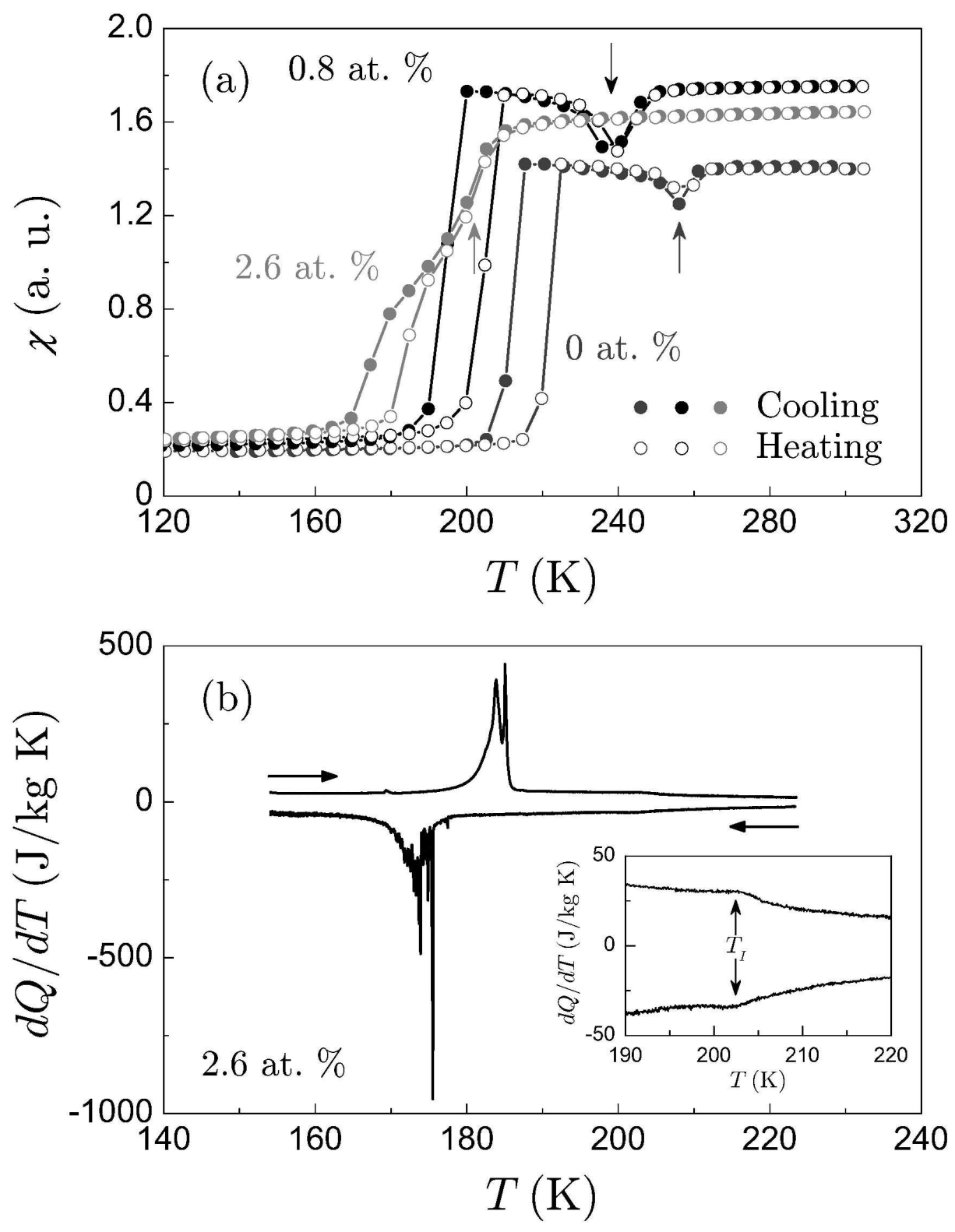

Figure 1 $147 \times 190 \mathrm{~mm}(600 \times 600 \mathrm{DPI})$ 

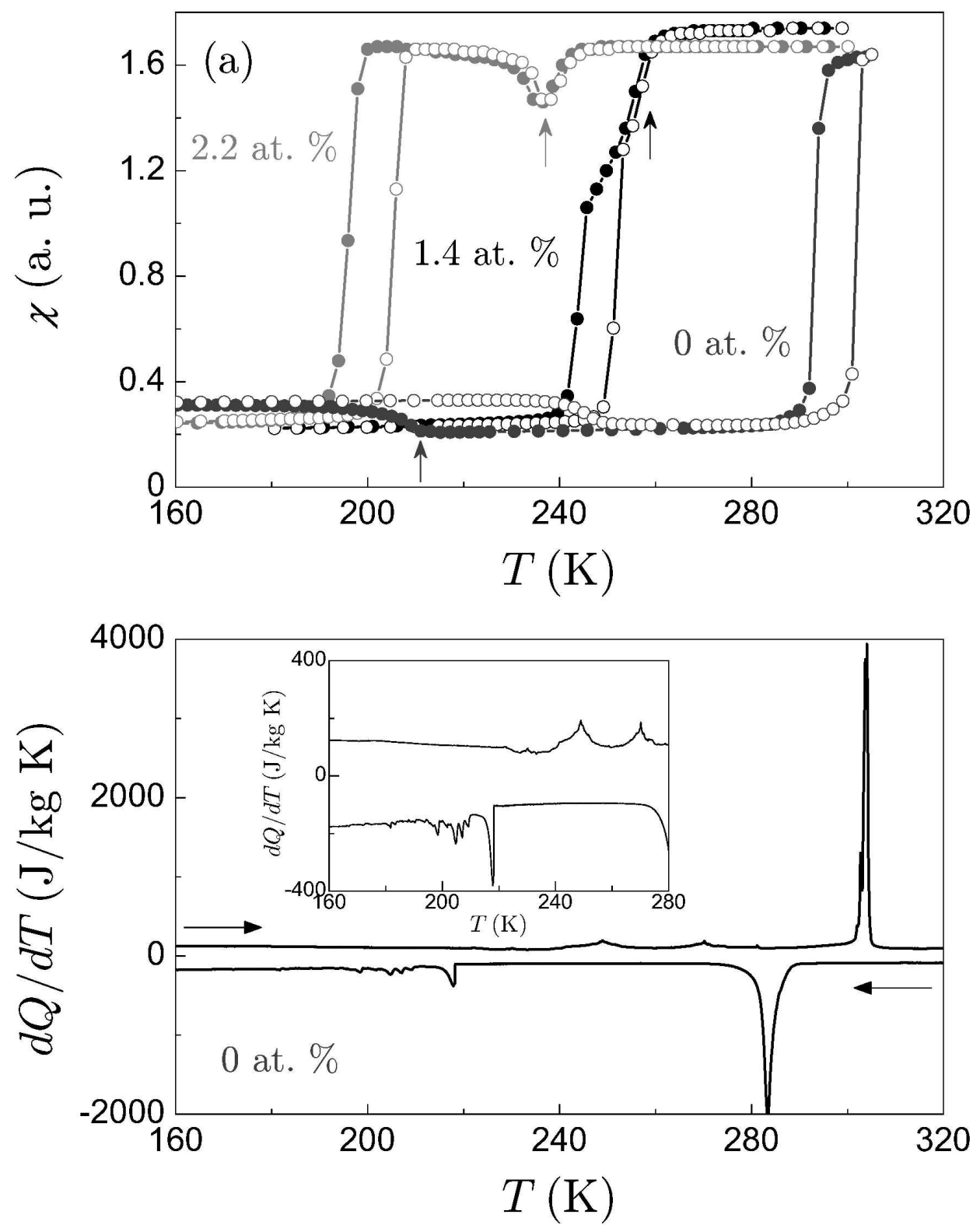

Figure 2 $148 \times 188 \mathrm{~mm}(600 \times 600 \mathrm{DPI})$ 

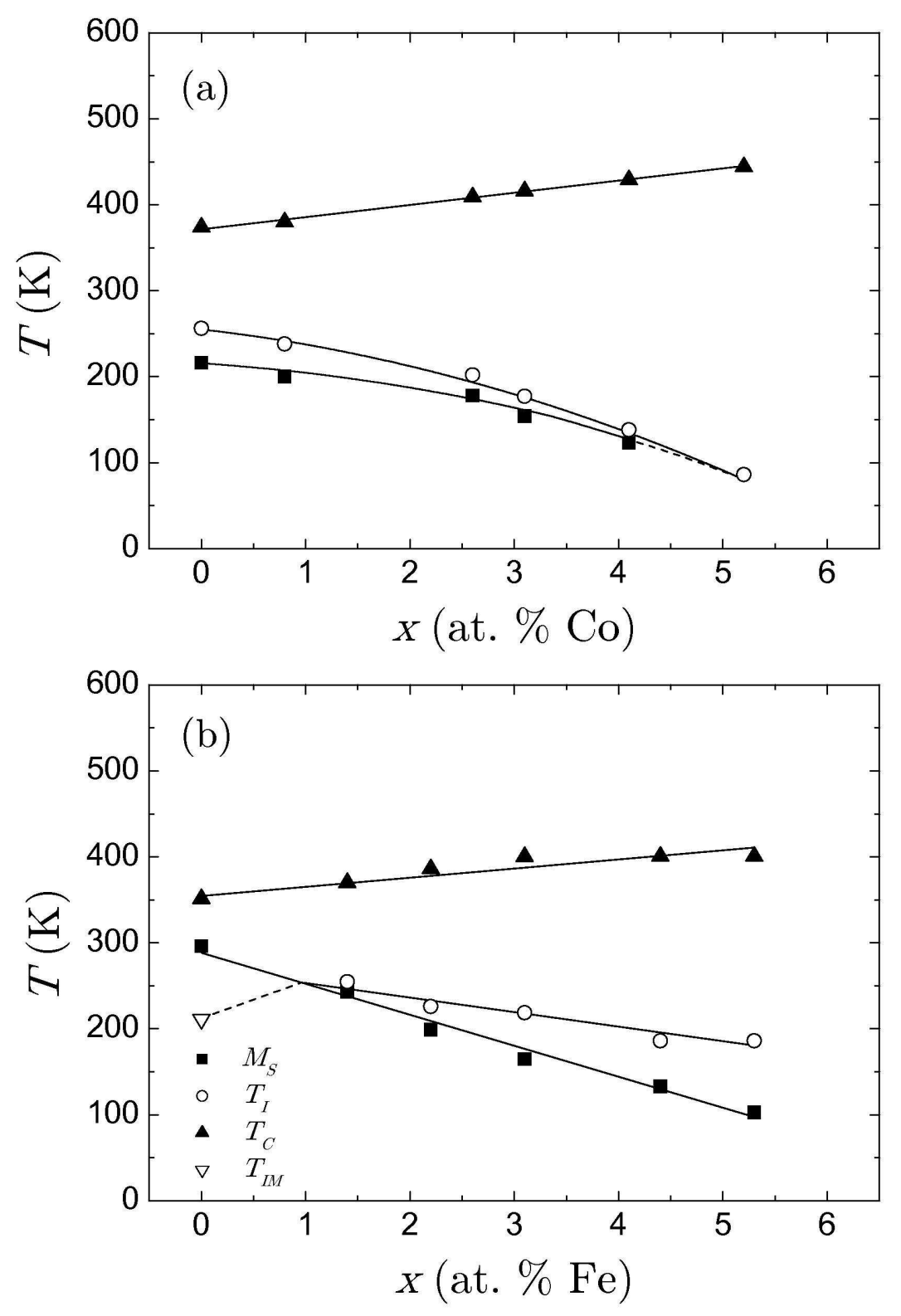

Figure 3

$71 \times 105 \mathrm{~mm}(600 \times 600$ DPI $)$ 


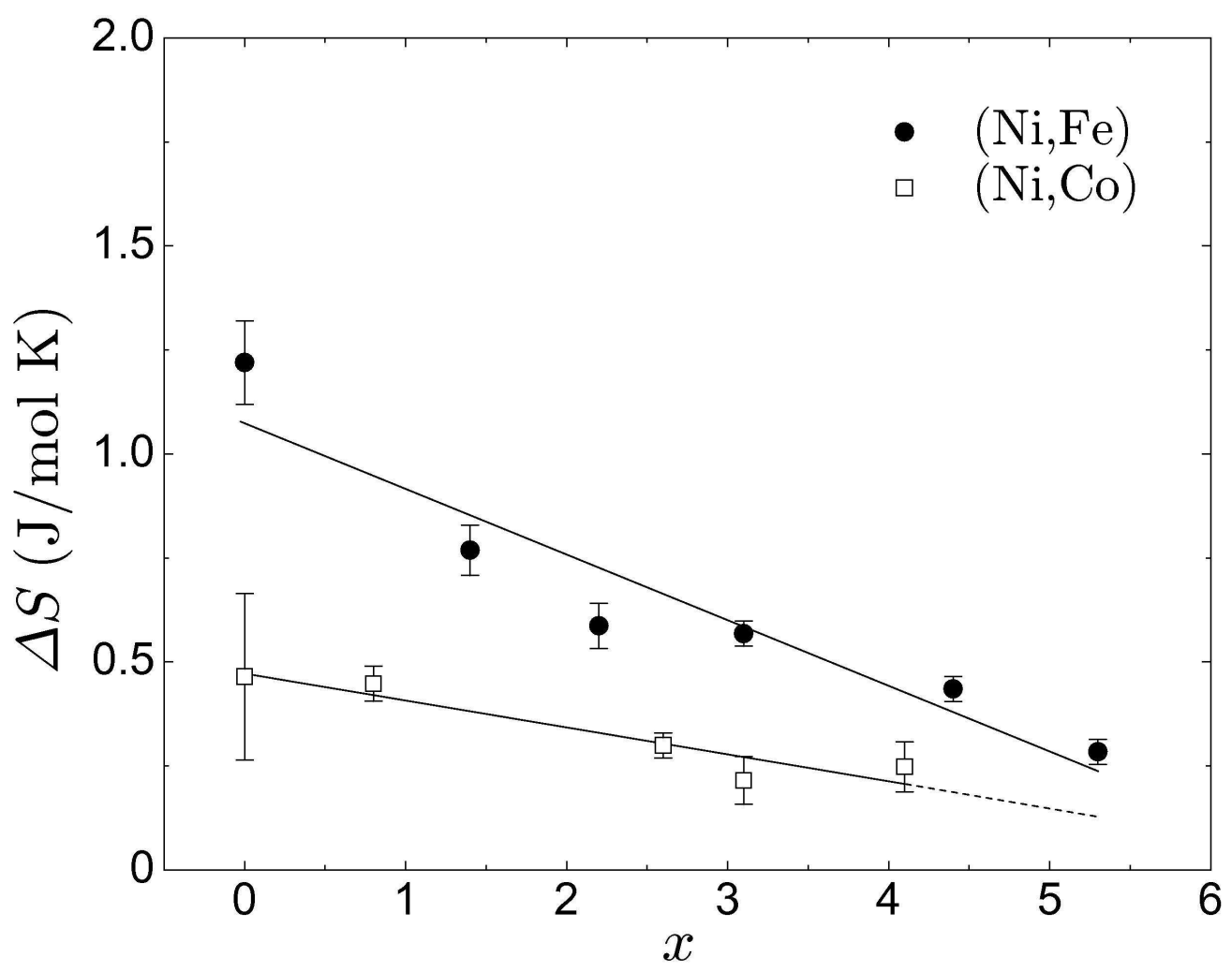

Figure 4 $105 \times 82 \mathrm{~mm}(600 \times 600 \mathrm{DPI})$ 

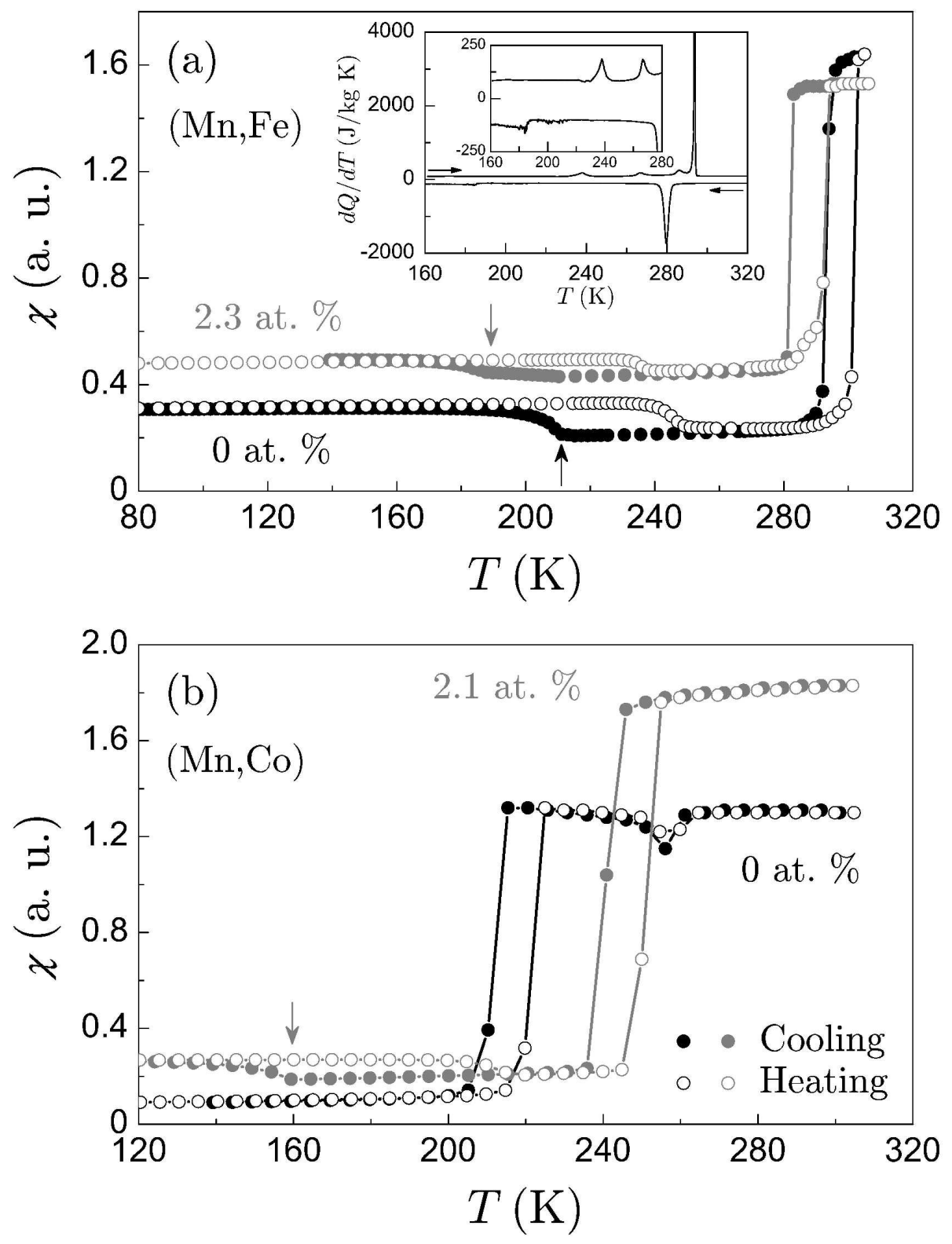

Figure 5 $142 \times 188 \mathrm{~mm}(600 \times 600$ DPI $)$ 

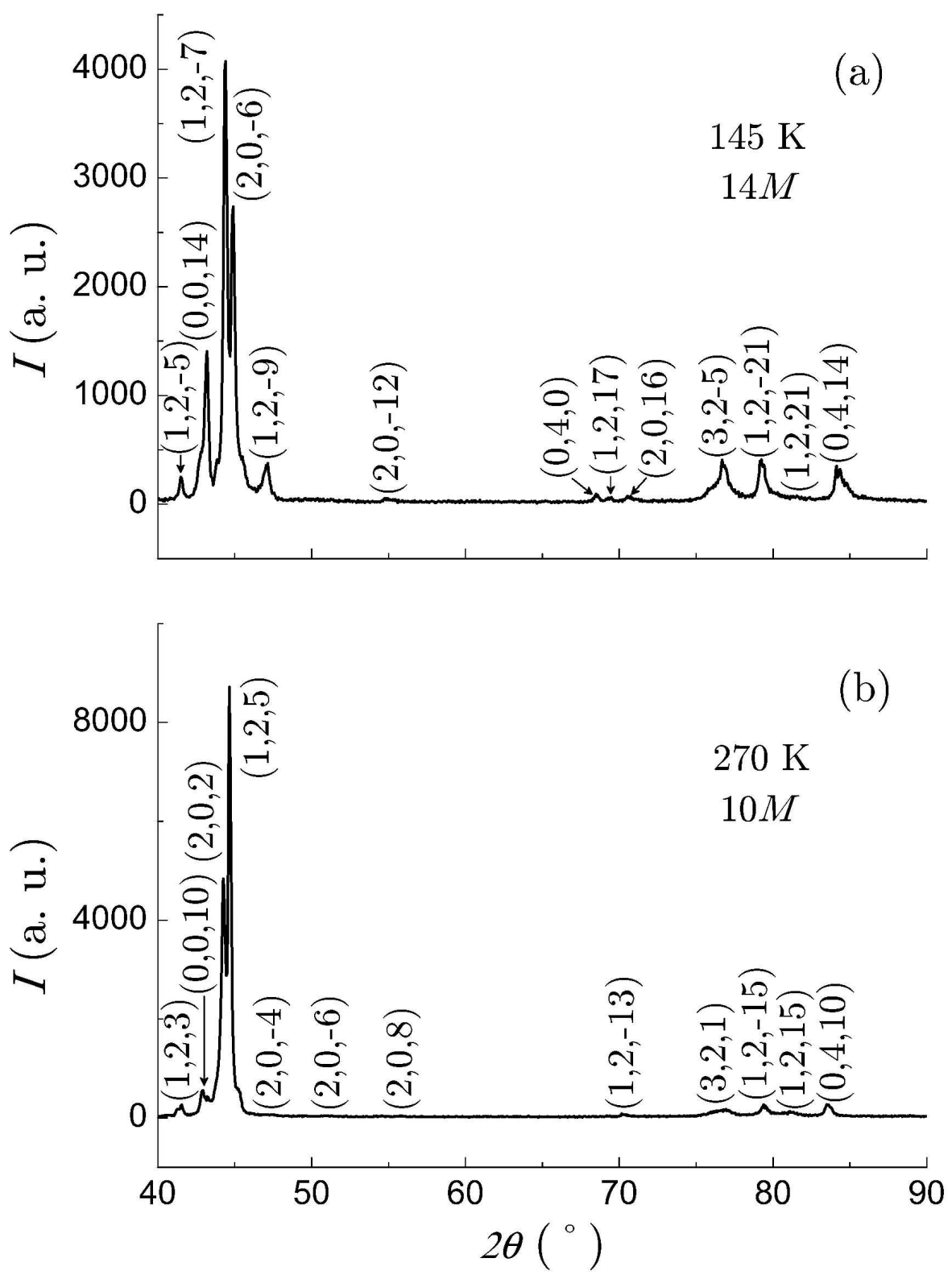

Figure 6 $144 \times 194 \mathrm{~mm}(600 \times 600 \mathrm{DPI})$ 

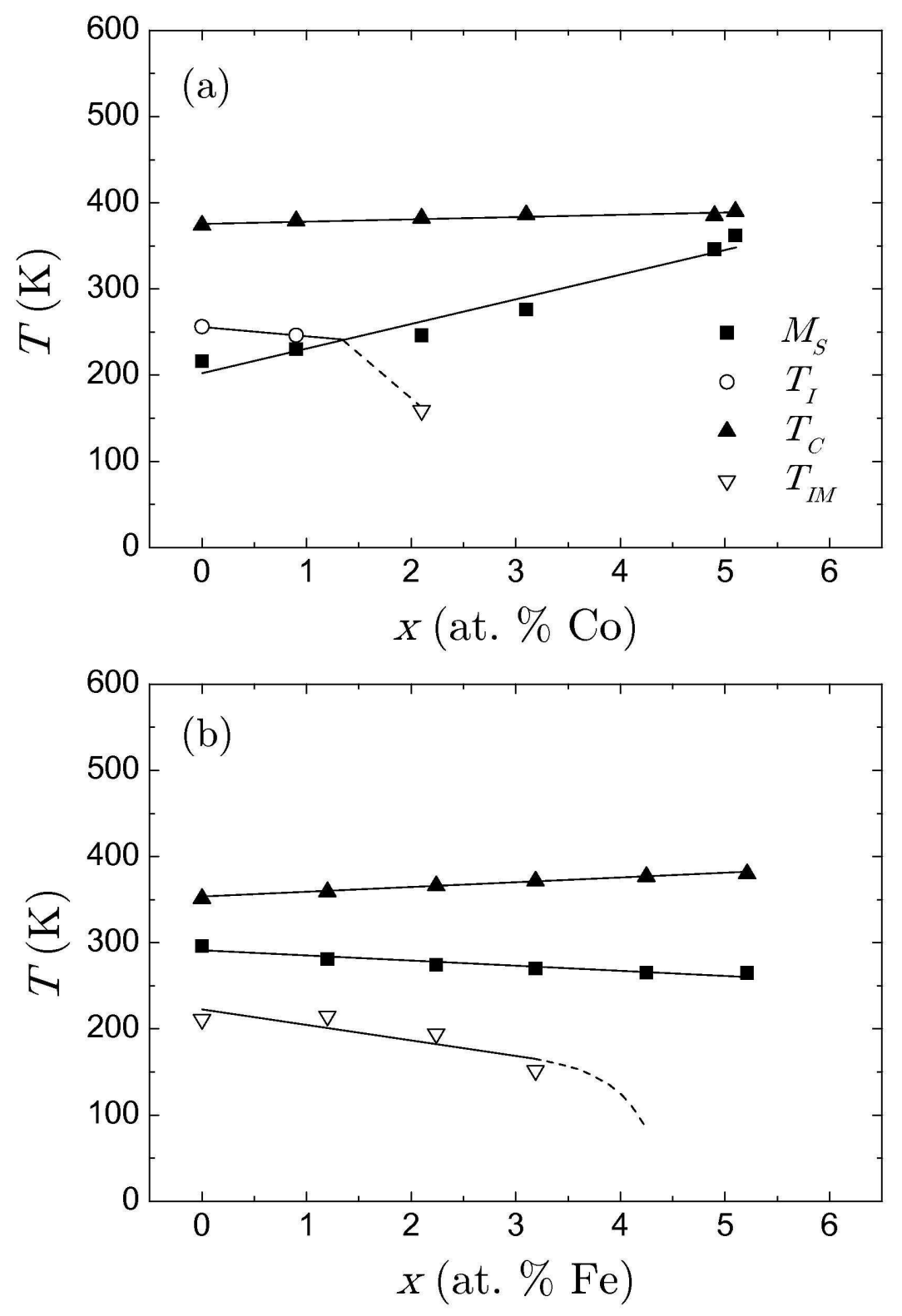

Figure 7

$71 \times 105 \mathrm{~mm}(600 \times 600$ DPI $)$ 


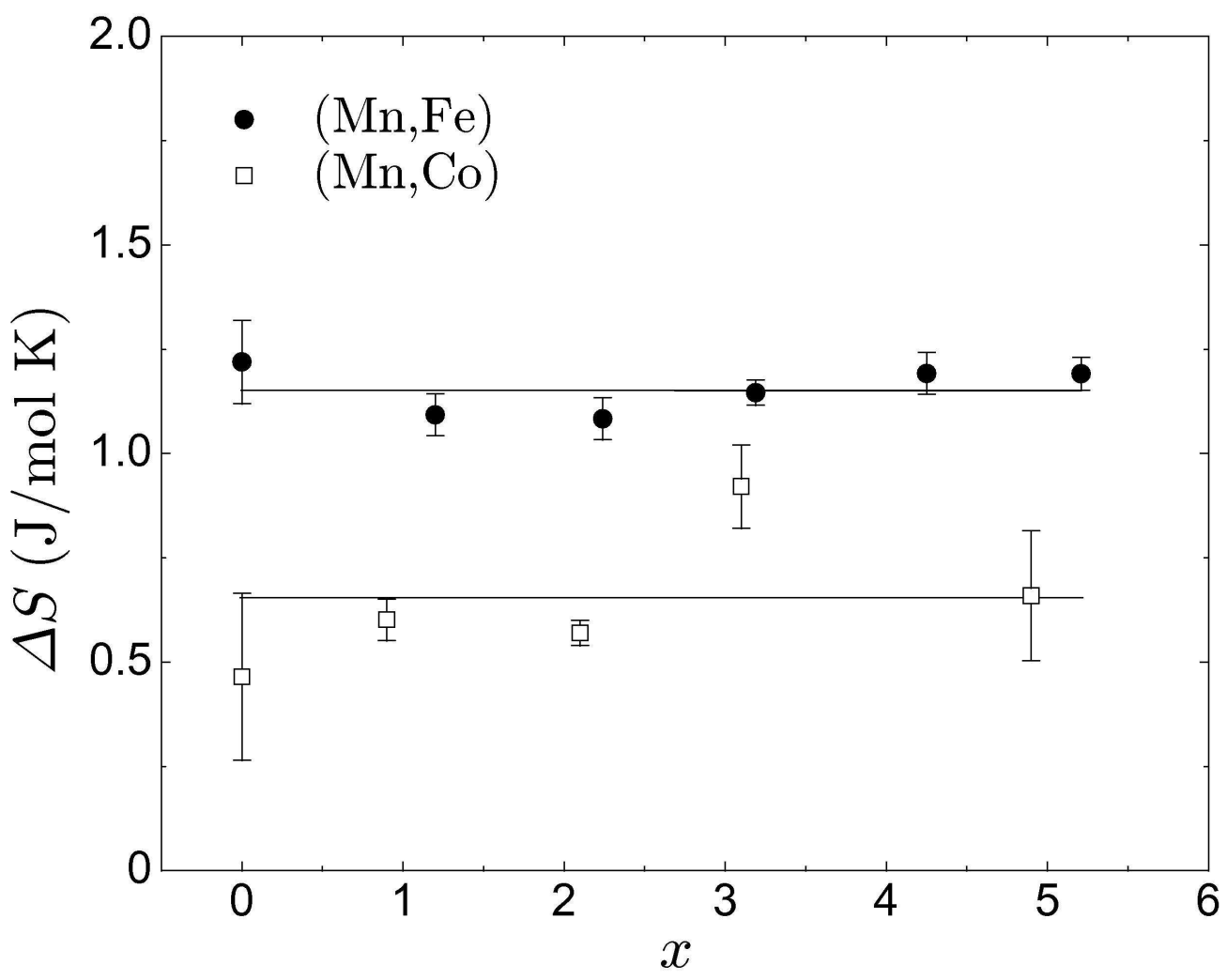

Figure 8 $105 \times 83 \mathrm{~mm}(600 \times 600 \mathrm{DPI})$ 

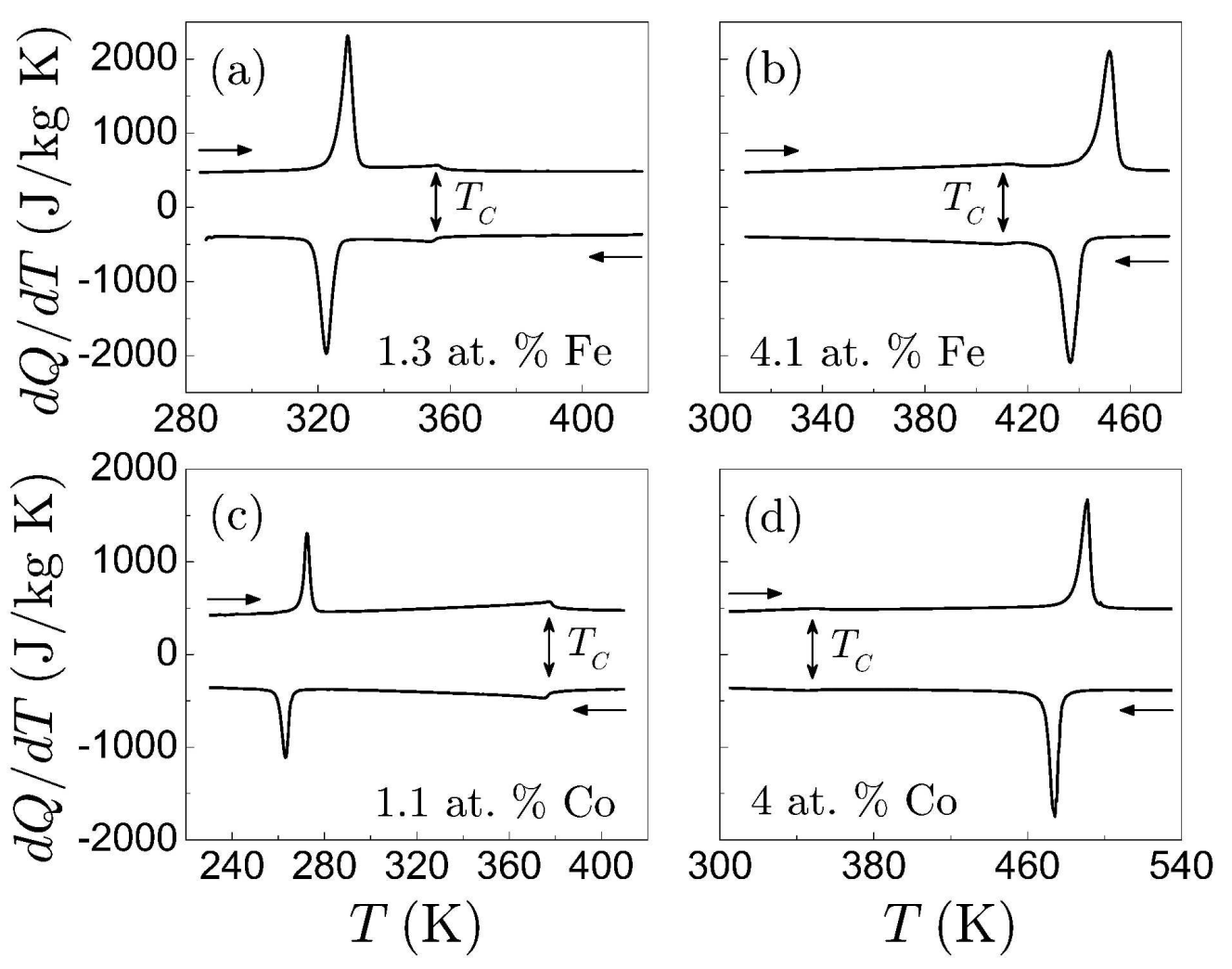

Figure 9

$239 \times 185 \mathrm{~mm}(600 \times 600 \mathrm{DPI})$ 

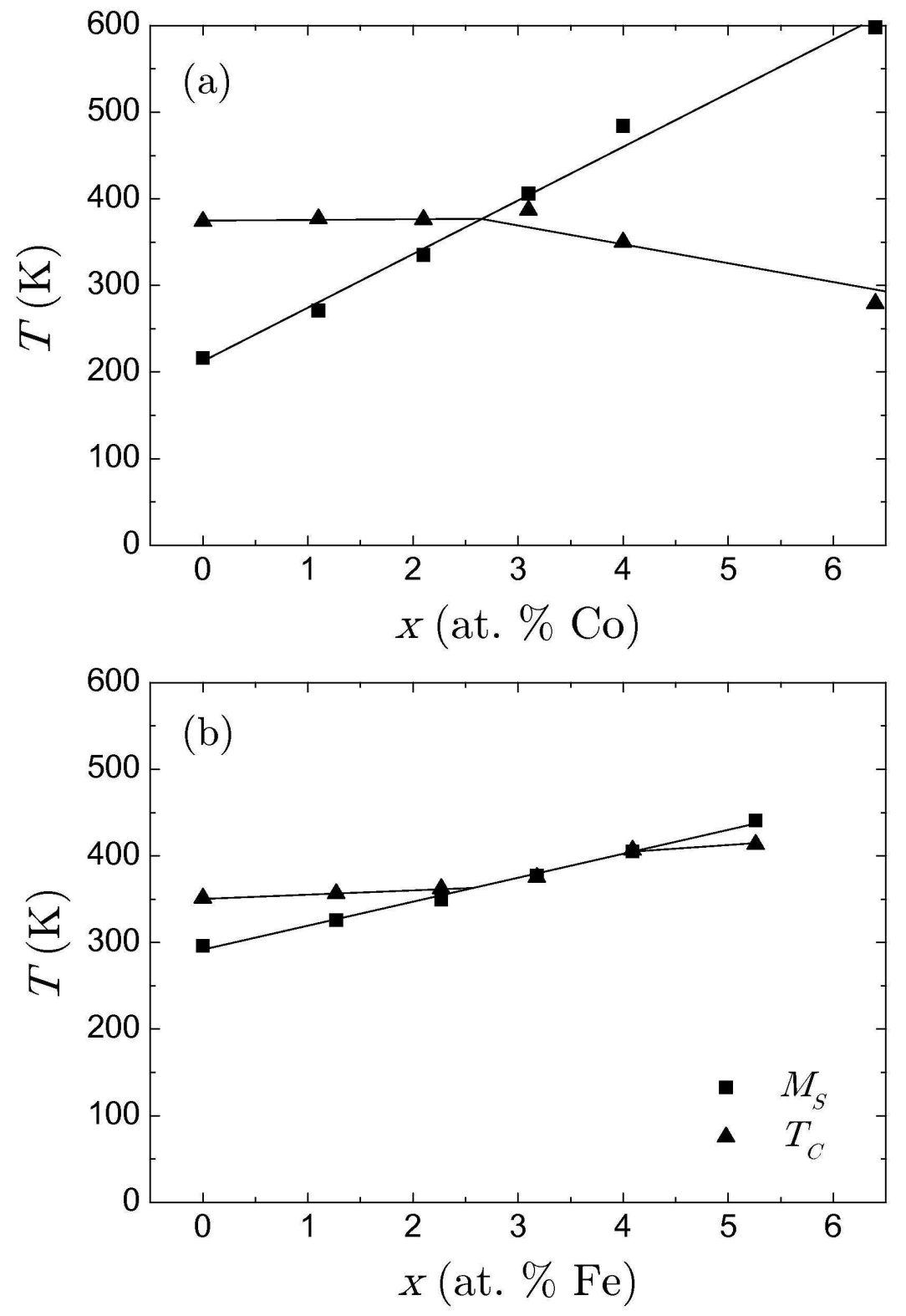

Figure 10

$71 \times 105 \mathrm{~mm}(600 \times 600 \mathrm{DPI})$ 


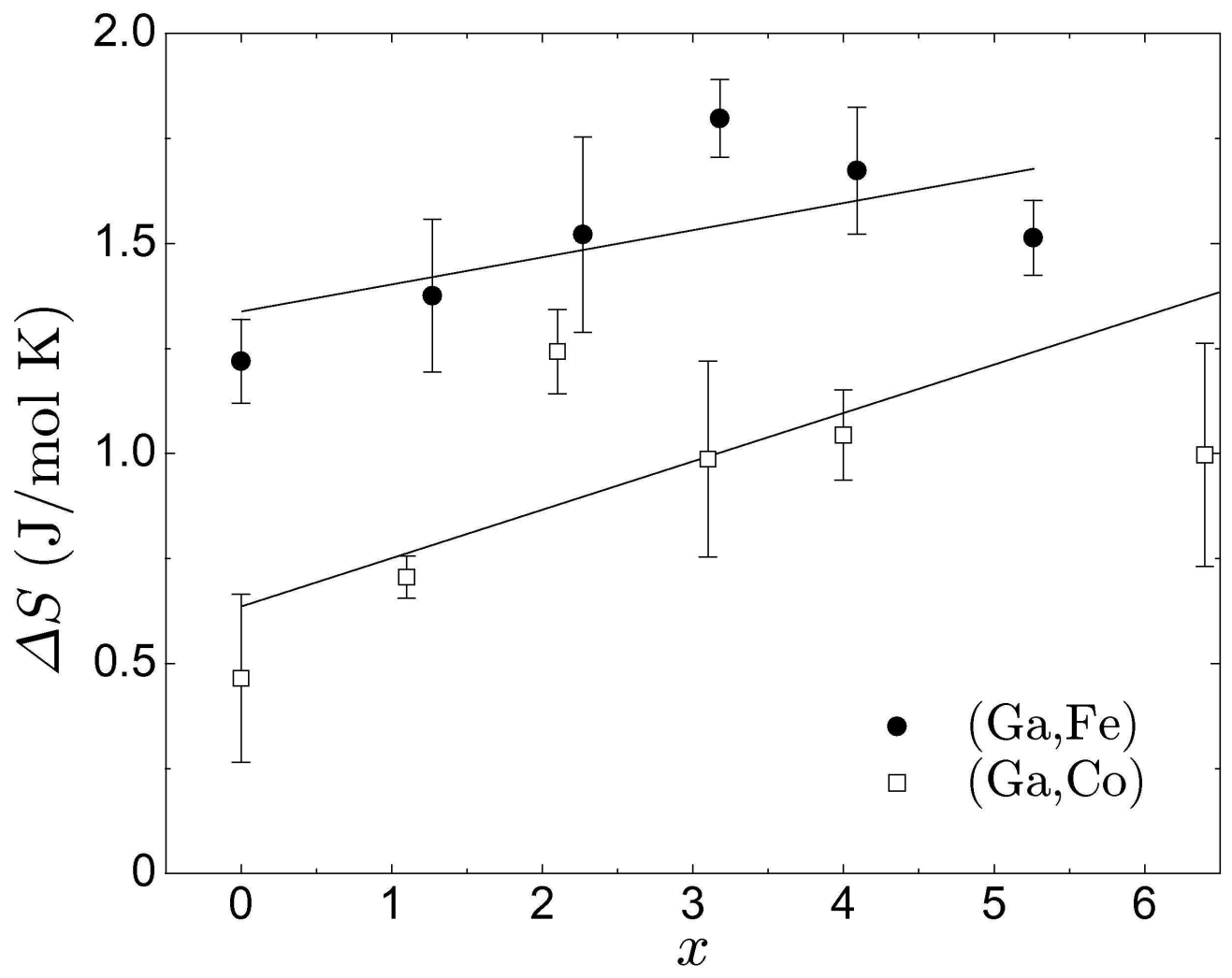

Figure 11 $104 \times 82 \mathrm{~mm}(600 \times 600$ DPI $)$ 

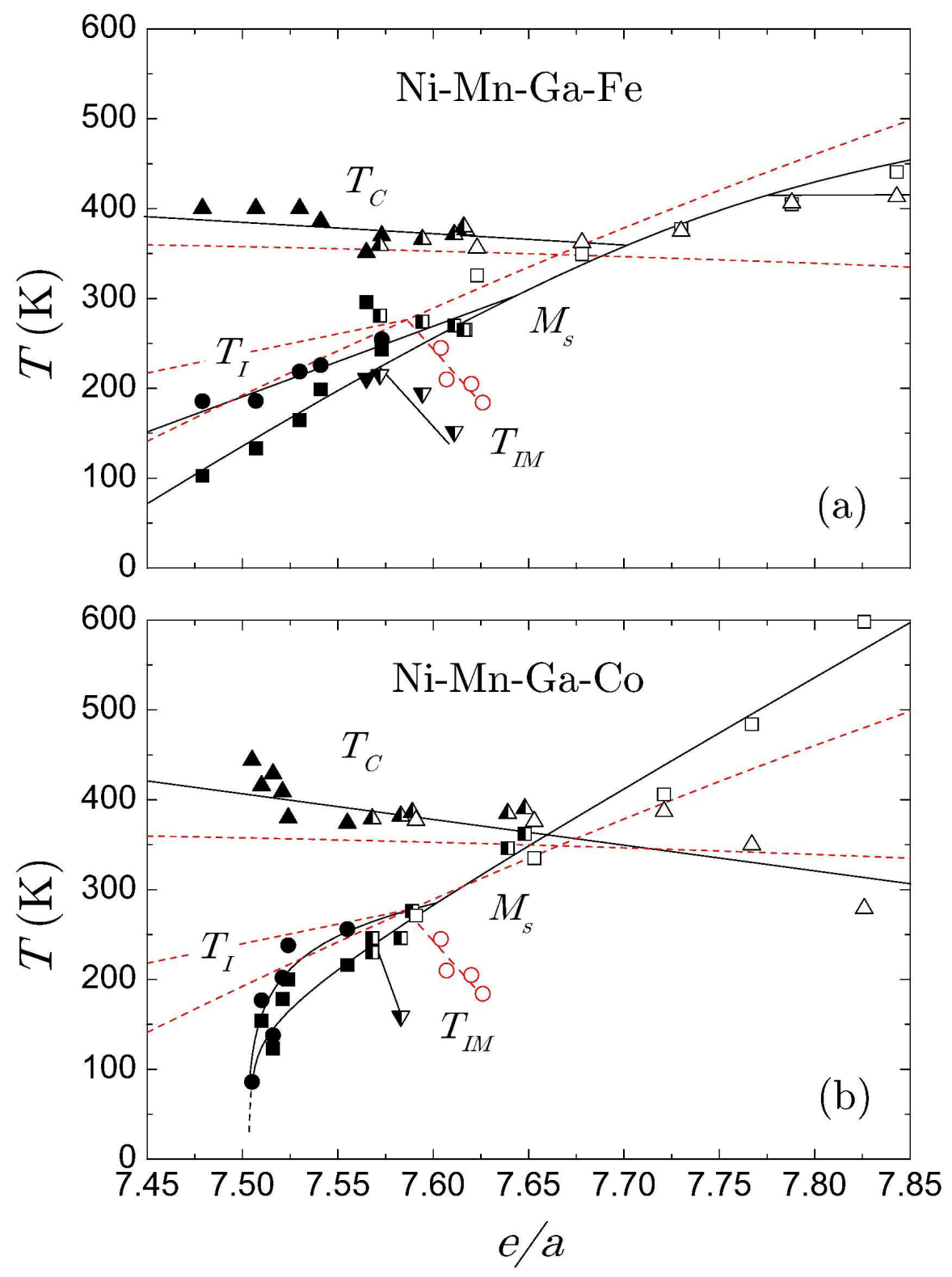

Figure 12

$144 \times 196 \mathrm{~mm}(600 \times 600 \mathrm{DPI})$

http://mc.manuscriptcentral.com/pm-pml 

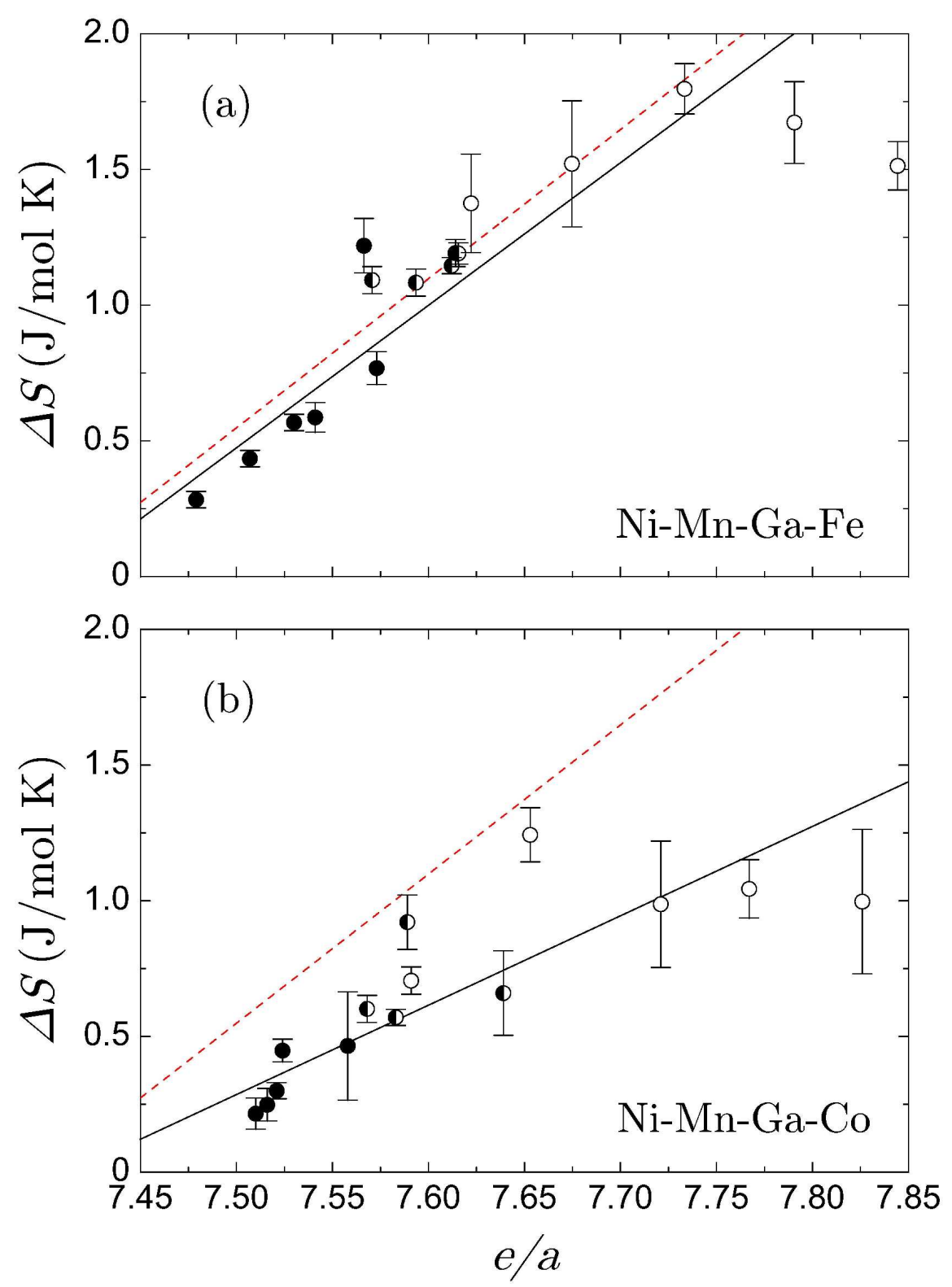

Figure 13

$143 \times 196 \mathrm{~mm}(600 \times 600 \mathrm{DPI})$ 